ARTICLE

https://doi.org/10.1038/s41467-020-16154-3

\title{
Light-powered Escherichia coli cell division for chemical production
}

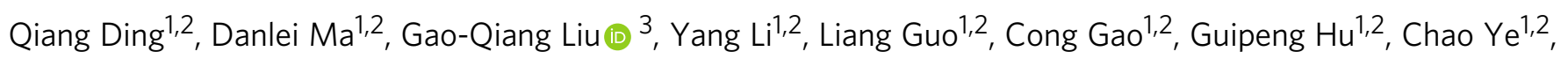
Jia Liu ${ }^{1,2}$, Liming Liu ${ }^{1,2,4} \&$ Xiulai Chen (1) ${ }^{1,2 凶}$

Cell division can perturb the metabolic performance of industrial microbes. The $\mathrm{C}$ period of cell division starts from the initiation to the termination of DNA replication, whereas the D period is the bacterial division process. Here, we first shorten the $C$ and $D$ periods of $E$. coli by controlling the expression of the ribonucleotide reductase $\mathrm{NrdAB}$ and division proteins FtsZA through blue light and near-infrared light activation, respectively. It increases the specific surface area to $3.7 \mu \mathrm{m}^{-1}$ and acetoin titer to $67.2 \mathrm{~g} \cdot \mathrm{L}^{-1}$. Next, we prolong the $C$ and $D$ periods of $E$. coli by regulating the expression of the ribonucleotide reductase $\mathrm{NrdA}$ and division protein inhibitor SulA through blue light activation-repression and near-infrared (NIR) light activation, respectively. It improves the cell volume to $52.6 \mu \mathrm{m}^{3}$ and poly(lactate-co-3hydroxybutyrate) titer to $14.31 \mathrm{~g} \cdot \mathrm{L}^{-1}$. Thus, the optogenetic-based cell division regulation strategy can improve the efficiency of microbial cell factories.

\footnotetext{
${ }^{1}$ State Key Laboratory of Food Science and Technology, Jiangnan University, 214122 Wuxi, China. ${ }^{2}$ Key Laboratory of Industrial Biotechnology, Ministry of Education, Jiangnan University, 214122 Wuxi, China. ${ }^{3}$ Hunan Provincial Key Laboratory for Forestry Biotechnology, Central South University of Forestry and Technology, 410004 Changsha, China. ${ }^{4}$ National Engineering Laboratory for Cereal Fermentation Technology, Jiangnan University, 214122 Wuxi, China.

凶email: xlchen@jiangnan.edu.cn
} 
$\mathrm{M}$ icrobial cell factories offer an economic and environmentally friendly method for producing valuable chemicals, including biofuels, fine chemicals, and pharmaceuticals, from renewable feedstock ${ }^{1,2}$. To maximize the efficiency of microbial cell factories, a series of strategies have been developed, including traditional breeding ${ }^{3}$, adaptive evolution $^{4}$, synthetic biology 5,6 , and metabolic engineering ${ }^{4,7}$. Among these strategies, metabolic engineering has proven to be the most efficient and feasible way in improving the performance of industrial microbes ${ }^{4,8,9}$. Recently, DCEO biotechnology ${ }^{10}$ is proposed for engineering industrial microbes, and mainly involves in four technical steps: pathway design, pathway construction, pathway evaluation, and pathway optimization. Based on this, metabolic engineering strategies can be adopted to engineer microbial cell factories for chemical production at DNA level (promoter engineering ${ }^{11}$ ), RNA level (transcription factor engineering and synthetic RNA switches ${ }^{12}$ ), protein level (protein engineering and cofactor engineering ${ }^{5}$ ), and cell level (morphology engineering ${ }^{13}$ and consortia engineering ${ }^{14}$ ). In these strategies, cell morphology can affect the efficiency of microbial cell factories at cell level by changing cell density ${ }^{15}$, mass transfer ${ }^{16}$, cell size ${ }^{13,16}$, and cell lysis ${ }^{17,18}$.

Cell morphology can be generally affected by culture conditions $^{19}$, nutrient components ${ }^{20}$, cell division ${ }^{21}$, and cell metabo$\mathrm{lism}^{22-24}$. Previous studies on regulating cell morphology are mainly divided into three aspects: (1) Nutritional regulation: carbon sources, nitrogen sources, and metal ions can be used to regulate cell growth and biomass density by supplying essential components ${ }^{15}$; (2) Mechanical regulation: micro-particle cultivation and fermenter pressure play important roles in changing the culture rheology and oxygen transfer rate by affecting nutrient assimilation and mass transfer ${ }^{15,19}$; and (3) Skeleton protein regulation: skeleton proteins can alter cell width and cell lysis by perturbing cell membrane synthesis ${ }^{25}$. On the other hand, bacteria can tightly coordinate various events during cell cycle to control their cell morphology 26,27 . There are two key stages in the bacterial cell cycle: the $C$ period starts from the initiation to the termination of DNA replication, and the D period is the bacterial division process ${ }^{21}$. The $\mathrm{C}$ and $\mathrm{D}$ periods of cell division can affect cell morphology by perturbing dNTP synthesis or the assembly of Escherichia coli divisomes ${ }^{21,28}$. As a result, cell growth or cell volume is efficiently improved for chemical production ${ }^{13,29,30}$. Previous studies have demonstrated that overexpression of the division-related proteins-FtsZ, FtsQ, FtsA, and FtsN-or ribonucleotide reductases-NrdA, NrdB, and NrdD - can shorten the $\mathrm{C}$ and $\mathrm{D}$ periods. In addition, weak expression of $\mathrm{NrdA}, \mathrm{NrdB}$, and NrdD or overexpression of the division protein inhibitors of SulA, MinC, MinD, MinE, and FtsH can prolong the C and D periods $^{30-32}$ (Supplementary Note 1 ). Thus, how to change the cell morphology by regulating the $\mathrm{C}$ and $\mathrm{D}$ periods is interesting for chemical production. Optogenetics is an efficient strategy for regulating cell phenotypes to enhance the chemical production at multiple levels in a noninvasive, reversible, and spatiotemporal manner. For example, blue light-mediated optogenetics, far-red light-regulated CRISPR technology, and light-based metabolic flux regulation have been used for isobutanol production ${ }^{33}$, live cell therapy ${ }^{34}$, and deoxyviolacein biosynthesis ${ }^{35}$, respectively. These studies indicate that the optogenetics-based cell division may be a promising strategy for improving the efficiency of chemical production.

In this study, we show that the $\mathrm{C}$ and $\mathrm{D}$ periods of cell division can be shortened or prolonged through optogenetic regulation. The specific surface area (SSA) of E. coli is engineered to drive acetoin production by shortening the $\mathrm{C}$ and $\mathrm{D}$ period with a blue light activation and near-infrared (NIR) light activation system (BANA). The cell volume of $E$. coli is engineered to increase poly (lactate-co-3-hydroxybutyrate) production by prolonging the $\mathrm{C}$ and D periods with a blue light activation-repression and NIR light activation system (BARNA). The optogenetics-based cell division strategy can increase chemical production via microbial cell factories.

\section{Results}

Screening cell division genes. The 14 genes involved in the $\mathrm{C}$ and $\mathrm{D}$ periods of cell division were divided into two distinct groups. The first group included nine overexpressed genes $(n r d A B, n r d A$, $n r d B, n r d D, f t s Z A, f t s Z, f t s A, f t s Q$, and $f t s N)$, which can stimulate dNTP synthesis and E. coli divisome assembly ${ }^{21}$. Genes in the second group included the weakly expressed $n r d A B, n r d A, n r d B$, and $n r d D$ and overexpressed $\operatorname{sulA}, \min C, \min D, \min E$, and $f t s H$. These genes can perturb dNTP synthesis and Z-ring assembly ${ }^{36,37}$, thus are involved in prolonging cell division.

As illustrated in Fig. 1, independent overexpression of $n r d A B$, $n r d A, n r d B, n r d D, f t s Z A, f t s Z, f t s A, f t s Q$, and $f t s N$ in E. coli JM109 shortened cell division (Supplementary Data 1 and 2). As a result, the periods of cell division, mean cell length (MCL), mean surface area, and mean cell volume (MCV) were decreased. The SSA, cell count (c.f.u), cell growth $\left(\mathrm{OD}_{600}\right)$, and dry cell weight (DCW) were increased. In addition, the mean cell width (MCW) was not changed (Fig. 1e, f, Supplementary Figs. 1A, B and $4 \mathrm{~A}$ ). However, when $n r d A B$ (or ftsZA) was overexpressed, an obvious difference was observed in cell morphology. Compared with the control strain, the periods of cell division, mean surface area, MCV of the engineered strains overexpressing $n r d A B$ (or fts $Z A$ ) were decreased by $39.73 \%$ (or $43.75 \%$ ), $31.66 \%$ (or $41.53 \%$ ), and $40.35 \%$ (or 52.94\%), respectively (Fig. 1a-d, Supplementary Fig. 3A). In addition, the SSA, c.f.u, $\mathrm{OD}_{600}$, and DCW were increased by $14.69 \%$ (or $24.25 \%$ ), $15.73 \%$ (or $25.84 \%$ ), $38.98 \%$ (or $37.29 \%$ ), and $38.98 \%$ (or $37.29 \%$ ), respectively (Fig. 1c, d, Supplementary Figs. 5A and 7A). These results indicated that overexpressing $n r d A B$ and fts $Z A$ could efficiently shorten the $C$ and $\mathrm{D}$ periods of cell division, respectively.

As showed in Fig. 2, the independent weak expression of $n r d A B, n r d A, n r d B$, and $n r d D$ in the corresponding E. coli JM109 mutant strains and the independent overexpression of sulA, $\min C, \min D, \min E$, and $f t s H$ in $E$. coli JM109 could prolong cell division (Supplementary Data 1 and 2). As a result, the periods of cell division, the MCL, mean surface area, and MCV were increased. The SSA, c.f.u, $\mathrm{OD}_{600}$, and DCW were decreased. In addition, those genes expression did not change MCW (Fig. 2e, f, Supplementary Figs. 2A, B, 4B). Among these strains, an obvious difference was showed in cell morphology by weak expression of $n r d A$ and overexpression of sulA. Compared with the control strain, the periods of cell division, mean surface area, MCV of the engineered strains with weak expression of $n r d A$ (or overexpression of sulA) were increased by $124.6 \%$ (or $271.8 \%$ ), $281.21 \%$ (or $776.87 \%$ ), and $384.57 \%$ (or $960.62 \%$ ), respectively (Fig. 2a-d, Supplementary Fig. 3B). In addition, the SSA, c.f.u, $\mathrm{OD}_{600}$, and DCW were decreased by $21.41 \%$ (or $17.74 \%$ ), $11.55 \%$ (or $31.05 \%$ ), $4.65 \%$ (or $5.81 \%$ ), and $4.65 \%$ (or $5.81 \%$ ), respectively (Fig. 2c, d, Supplementary Fig. 6A, 7B). Compared with E. coli JM109 with weak expression of $n r d A, n r d A B, n r d B$, and $n r d D$, the C period of E. coli JM109 with deletion of $n r d A, n r d A B, n r d B$, and $n r d D$ was increased by $102.77 \%, 51.58 \%, 59.28 \%$, and $18.53 \%$, respectively (Supplementary Fig. 3C, and Supplementary Note 2). These results suggested that weak expression of $n r d A$ and overexpression of sulA could efficiently prolong the C and D periods of cell division, respectively.

Finally, we investigated the effect of $n r d A B$ and $f t s Z A$ overexpression on shortening cell division and the effect of weak $n r d A$ expression and $s u l A$ overexpression on prolonging cell 

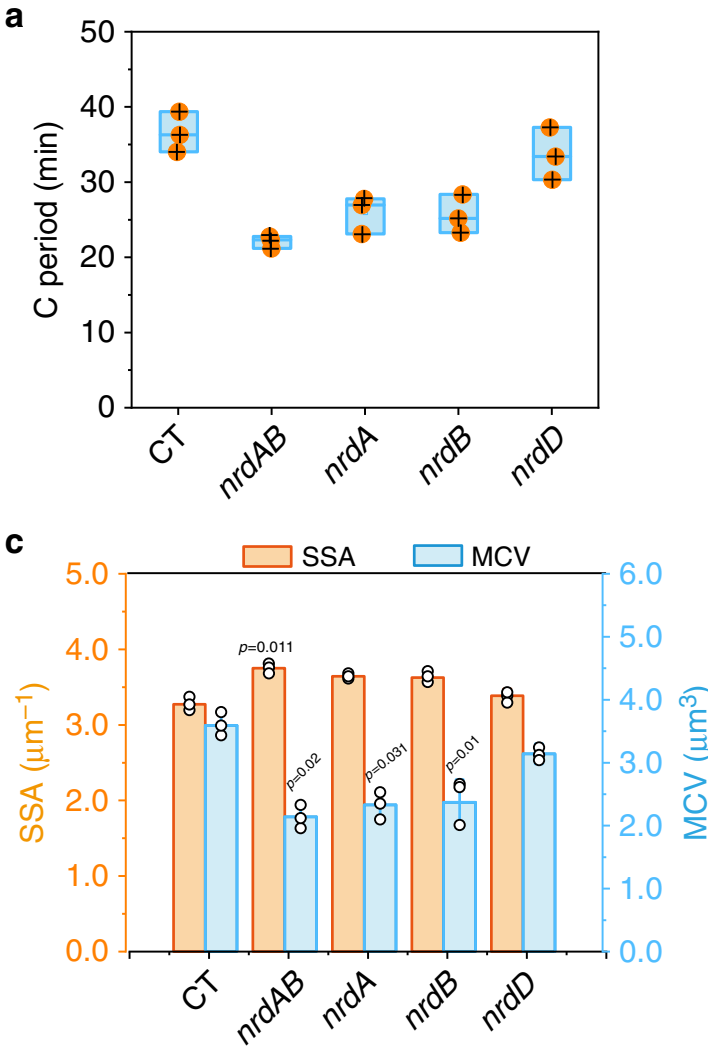
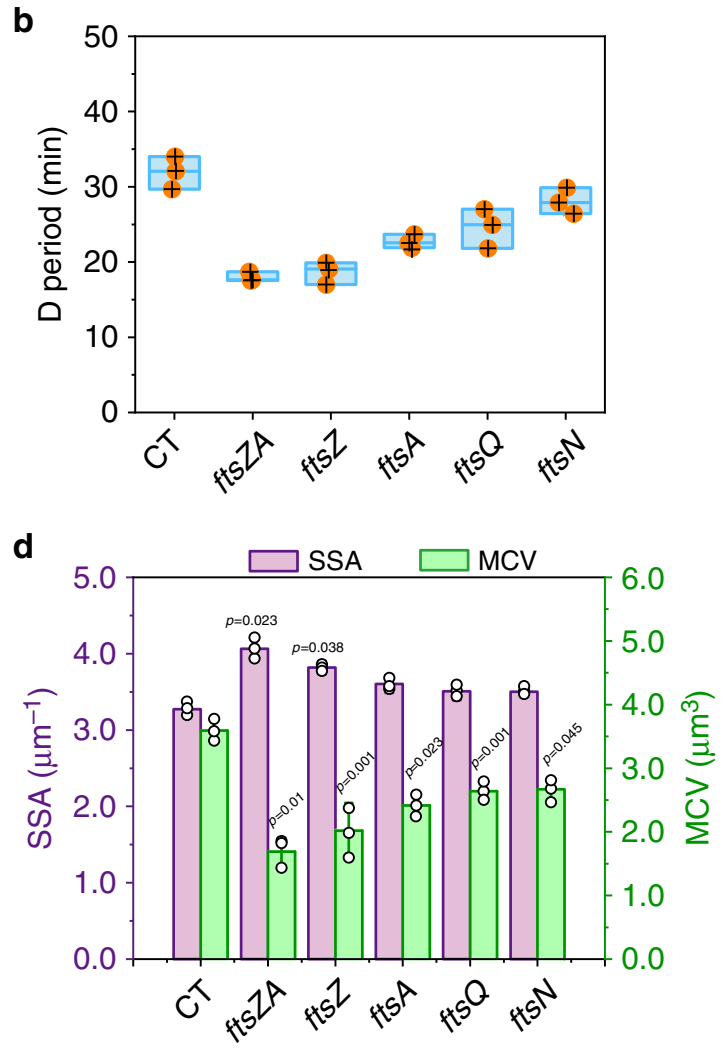

e

C period of cell division
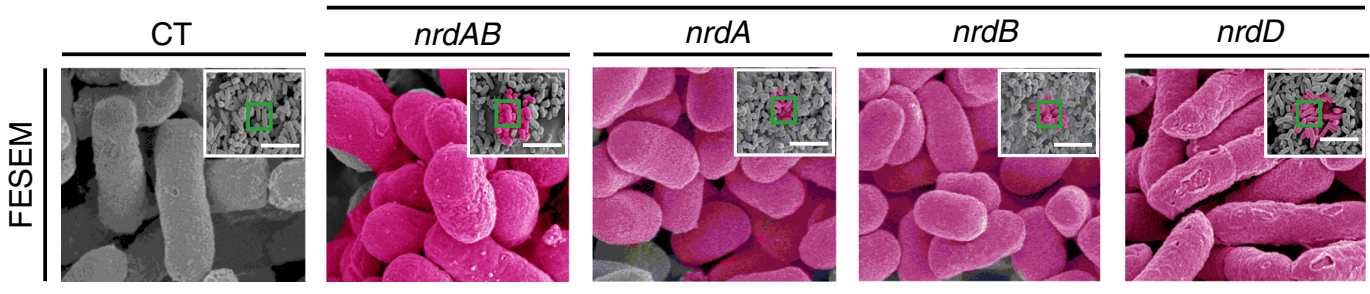

f

D period of cell division
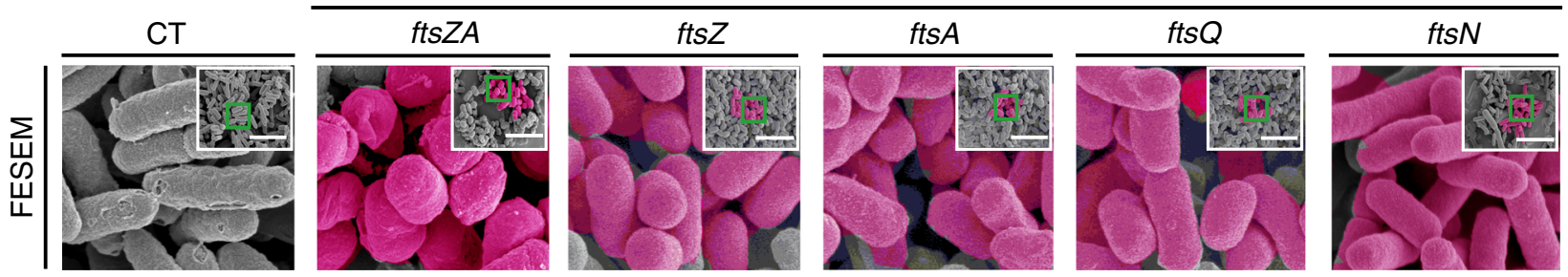

Fig. 1 Shortening the $\mathbf{C}$ and $\mathbf{D}$ periods of cell division by genetic manipulation. $\mathbf{a}, \mathbf{b}$ Effect of shortening the $C$ and $D$ periods of cell division on cell division. c, $\mathbf{d}$ Effect of shortening the $C$ and $D$ periods of cell division on the specific surface area (SSA) and mean cell volume (MCV), respectively. $\mathbf{e}, \mathbf{f}$ Confirming the morphological variations of all engineered strains by the filed emission scanning electron microscopy (FESEM). The pink color of FESEM was highlighted. The original pictures were shrinked into the top right corner of the enlarged pictures. $\mathbf{a}, \mathbf{b}$ The box plots define the minima, maxima, center, and bounds of box. e, $\mathbf{f}$ The scale bar is $5 \mu \mathrm{m}$. Significance ( $p$-value) was evaluated by two-sided $t$-test compared to CT. a-d Values were shown as mean \pm s.d. from three $(n=3)$ biological independent replicates. Information for each gene was provided in Supplementary Note 1. Source data are provided as a Source data file.

division. As shown in Fig. 3a, b, the simultaneous overexpression of $n r d A B$ and $f t s Z A$ increased the SSA to $4.12 \mu \mathrm{m}^{-1}$, and the weak expression of $n r d A$ and overexpression of sulA increased the $\mathrm{MCV}$ to $56.2 \mu \mathrm{m}^{3}$. However, the coexpression of $n r d A B+f t s Z A Q$ and $\operatorname{nrdAB}+$ ftsZAQN did not shorten the $\mathrm{C}$ and $\mathrm{D}$ periods or increase the SSA, c.f.u, or $\mathrm{OD}_{600}$ (Supplementary Fig. 8A, B, 9A). Thus, the $n r d A B+f t s Z A$ and $n r d A+$ sulA groups were chosen to shorten or prolong the $\mathrm{C}$ and $\mathrm{D}$ periods of cell division, respectively (Fig. 3c-f).

Constructing the basic tools for powering cell division. To achieve spatial, temporal, and reversible control of E. coli SSA and MCV, three basic optogenetics-based cell division regulation tools, a blue-light activation tool (BLAT), a blue-light repression 

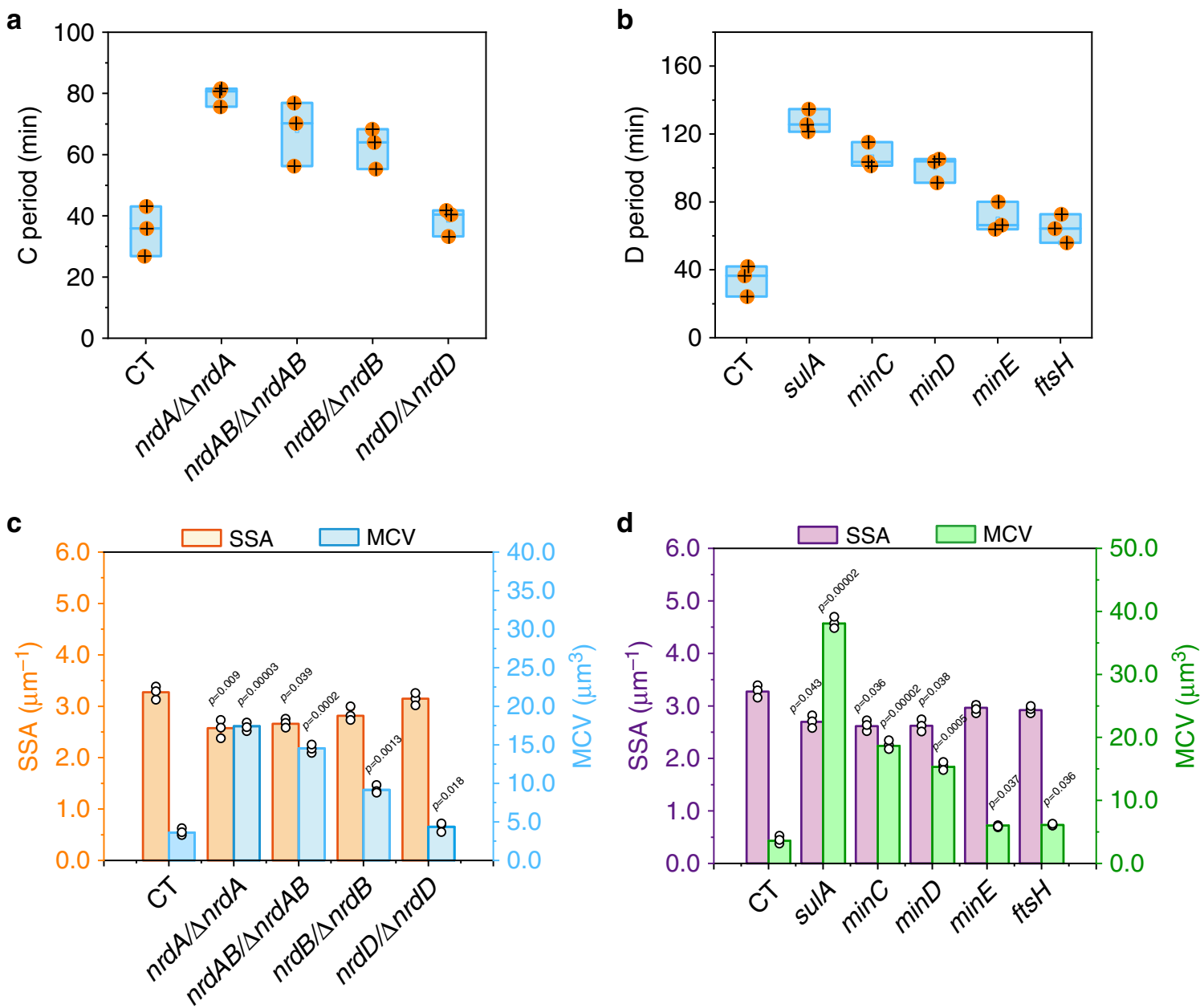

e

C period of cell division

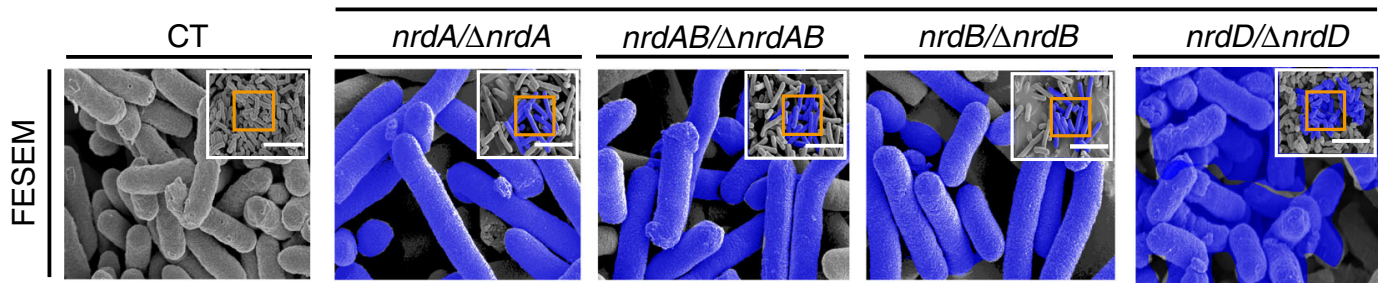

f

D period of cell division

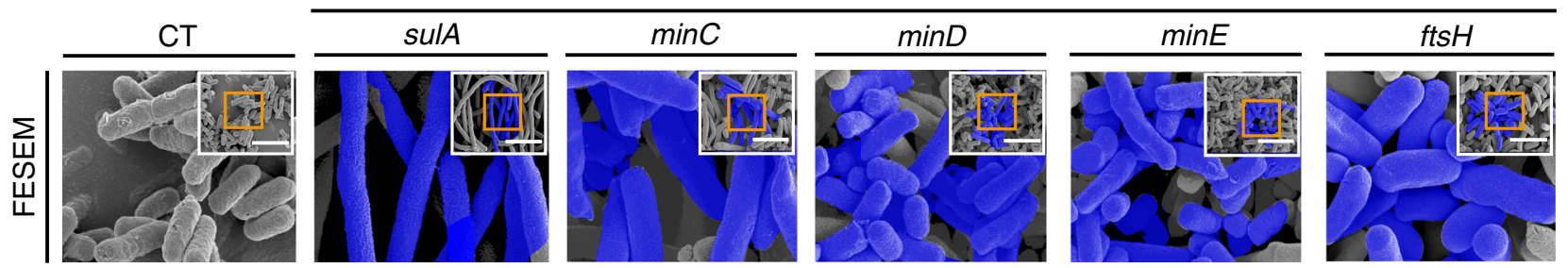

Fig. 2 Prolonging the $\mathbf{C}$ and $\mathbf{D}$ periods of cell division by genetic manipulation. $\mathbf{a}, \mathbf{b}$ Effect of prolonging the $C$ and $D$ periods of cell division on cell division. c, $\mathbf{d}$ Effect of prolonging the $C$ and D periods of cell division on the specific surface area (SSA) and mean cell volume (MCV). e, $\mathbf{f}$ Confirming the morphological variations of the all engineered strains by the FESEM. The blue color of FESEM was highlighted. For the original pictures were shrinked into the top right corner of the enlarged pictures. In $\operatorname{nrd} A / \Delta \operatorname{nrd} A, \operatorname{nrd} A B / \Delta \operatorname{nrd} A B, \operatorname{nrdB} / \Delta \operatorname{nrd} B$, and $\operatorname{nrdD} / \Delta \operatorname{nrdD}$ mutants, $\operatorname{nrd} A, \operatorname{nrd} A B$, $\operatorname{nrd} B$, and $\operatorname{nrdD} \operatorname{were}$ weakly expressed by low concentration IPTG $(10 \mu \mathrm{M})$, respectively. $\mathbf{a}, \mathbf{b}$ The box plots define the minima, maxima, center, and bounds of box. e, $\mathbf{f}$ The scale bar is $5 \mu \mathrm{m}$. Significance ( $p$-value) was evaluated by two-sided $t$-test, compared to CT. a-d Values are shown as mean \pm s.d. from three $(n=3)$ biological independent replicates. Information for each gene was provided in Supplementary Note 1. Source data are provided as a Source data file. 
a

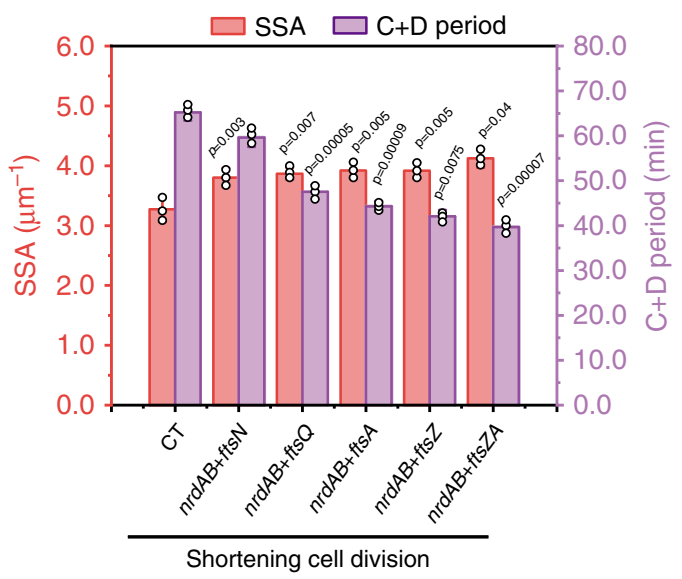

b

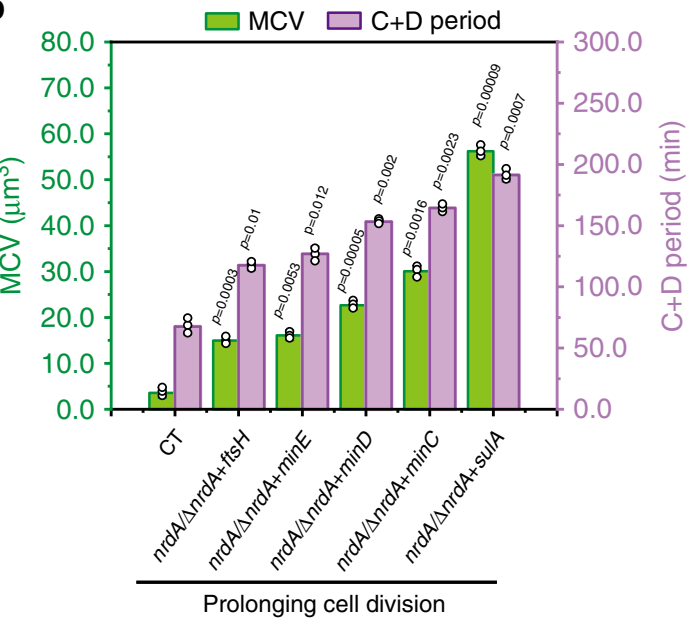

C

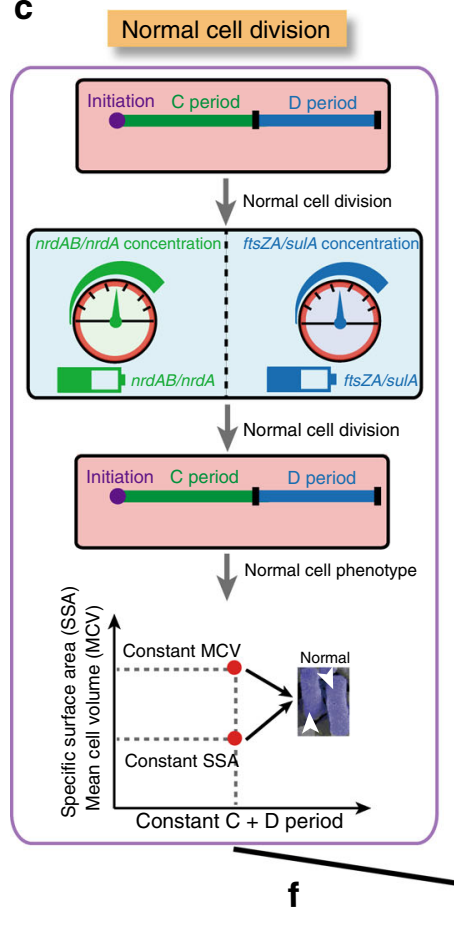

\section{d}

Shortening cell division

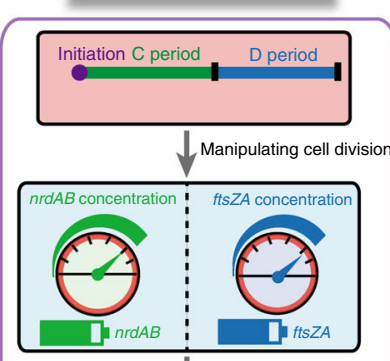

$\downarrow$ Shortening cell division

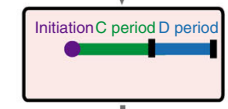

$\downarrow$ Powering cell phenotype

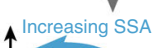

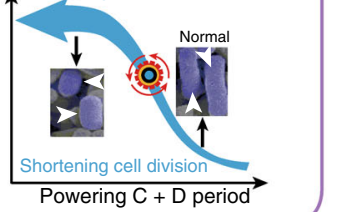

e

Prolonging cell division
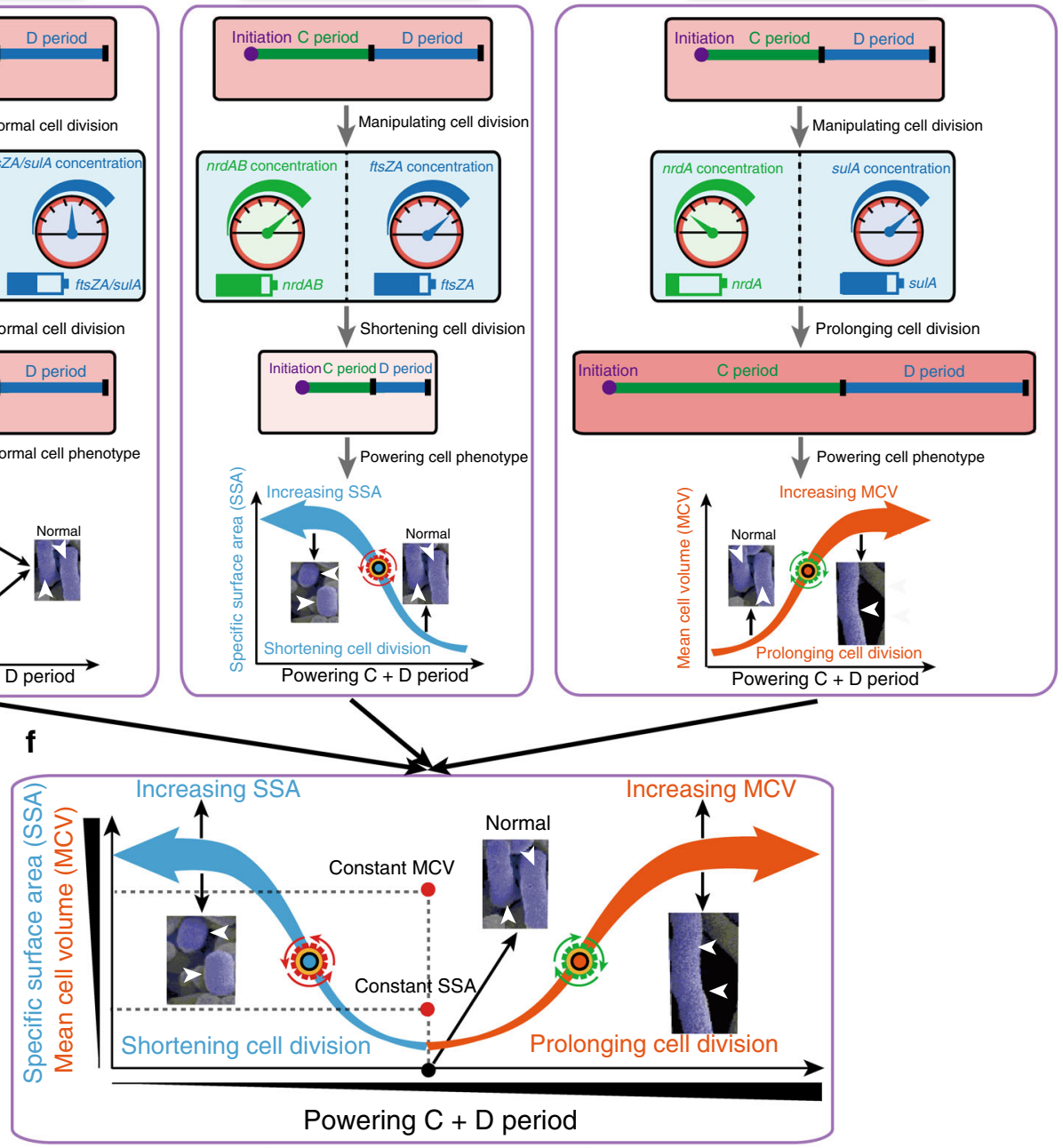

Powering cell division

Fig. 3 Combination of the $\mathbf{C}$ and $\mathbf{D}$ periods of cell division. a Combining the $C$ and $D$ periods for shortening cell division. $\mathbf{b}$ Combining the $C$ and $D$ periods for prolonging cell division. $\mathbf{c}$ Effect of normal cell division on cell morphology and the C+D periods. $\mathbf{d}$ Effect of shortening cell division on cell morphology and the $C+D$ periods. e Effect of prolonging cell division on cell morphology and the $C+D$ periods. $\mathbf{f}$ Engineering the $C+D$ periods of cell division for improving specific surface area (SSA) or mean cell volume (MCV). Significance ( $p$-value) was evaluated by two-sided $t$-test, compared to CT. a, $\mathbf{b}$ Values are shown as mean \pm s.d. from three $(n=3)$ biological independent replicates. Source data underlying Fig. $3 a, b$ are provided as a Source data file. 
a

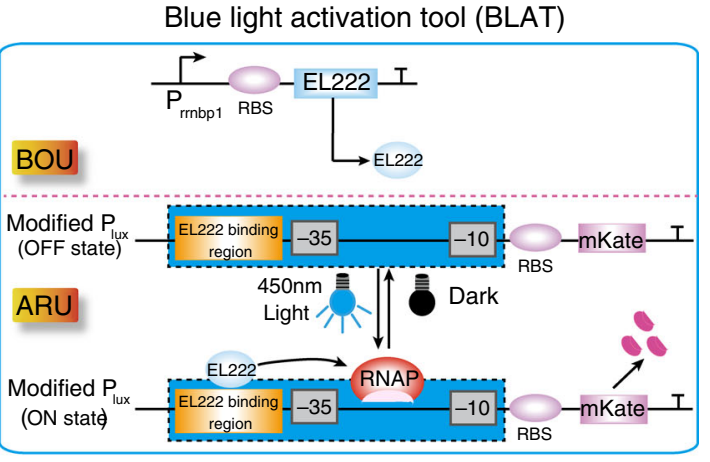

b

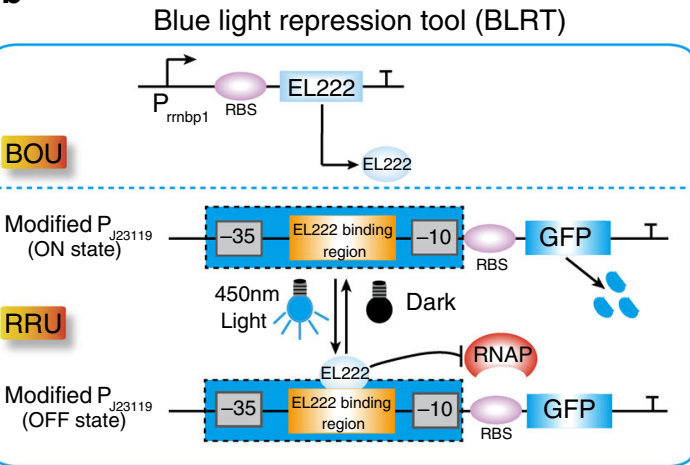

C

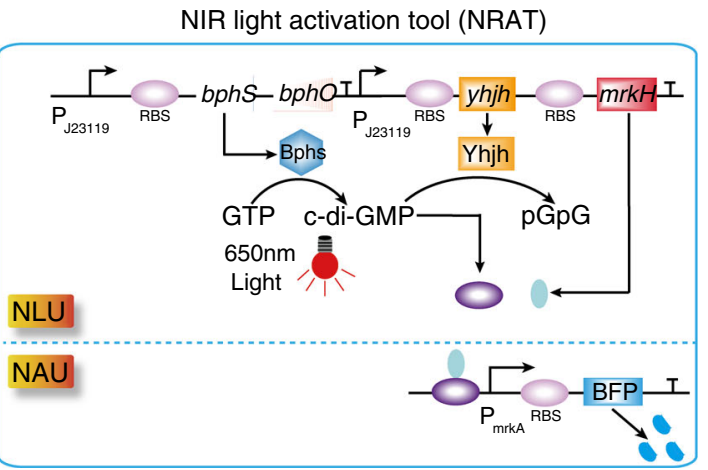

d

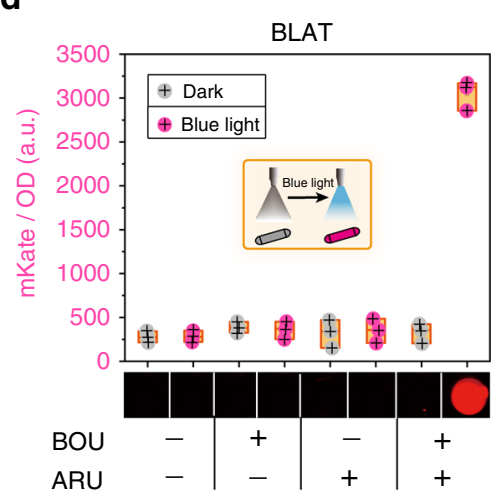

e

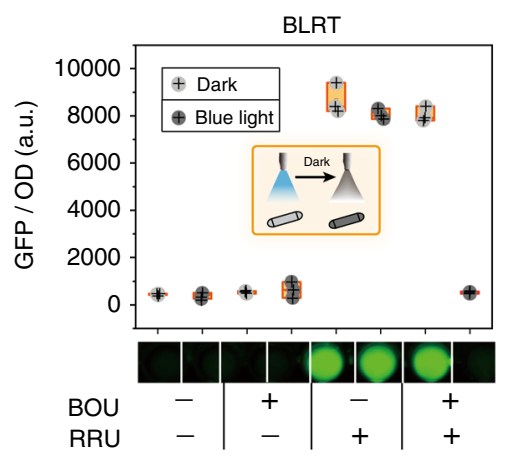

f

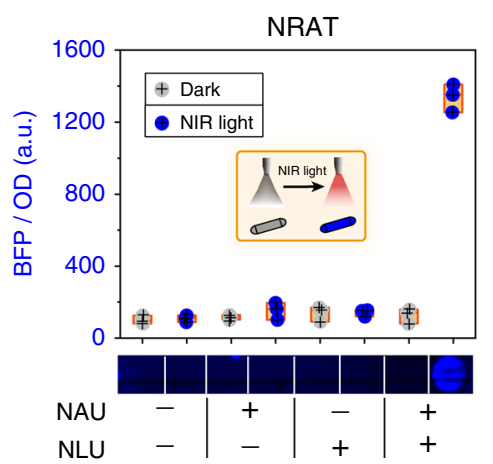

g
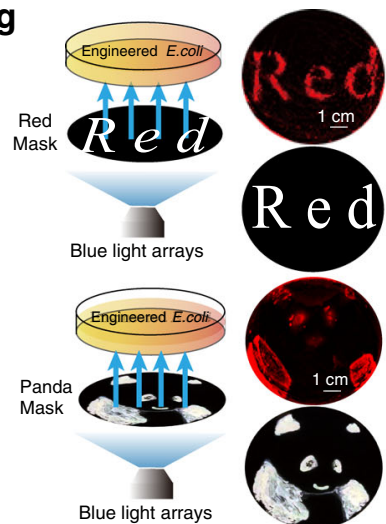

h

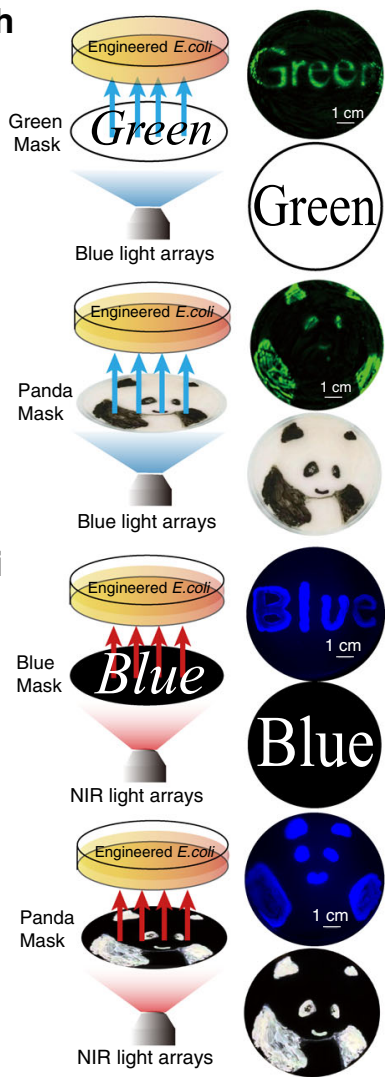

Fig. 4 The performance of three basic optogenetics tools. a-c The schematic diagram of BLAT (blue-light), BLRT (blue-light), and NRAT (NIR-light), respectively. Panels $\mathbf{a}$ and $\mathbf{b}$ are adapted from Jayaraman et al. ${ }^{38}$. d-f Fluorescence activation with BLAT, BLRT, and NRAT under dark, $0.8 \mathrm{~W} / \mathrm{cm}^{2}$ bluelight, and NIR-light, respectively. g-i Blue-light or NIR-light LEDs were mounted on the bottom of a photomask with a setup for pattern illumination. Red, green, blue, and chinese panda-patterned masks made from aluminum foil were placed on top of the photomask to illuminate culture plate. In this setup, photomasks were placed onto the bottom of the engineered $E$. coli-culture plate with BLAT, BLRT, and NRAT, respectively. $P_{J 23119}$ : constitutive promoter; $P_{\text {lux }}$ : quorum sensing promoter; $P_{\text {mrkA }}$ : MrkH-targeted promoter; EL222: light-sensitive protein from Erythrobacter litoralis; bphS: a c-di-GMP diguanylate cyclase from Rhodobacter sphaeroides; bphO: a heme oxygenase from Rhodobacter sphaeroides; yhjH: c-di-GMP PDE from E. coli; mrkH: a transcriptional factor from Klebsiella pneumoniae. The box plots define the minima, maxima, center, and bounds of box. $\mathbf{d}-\mathbf{f} n$ values are shown as mean \pm s.d. from three $(n=3)$ biological independent replicates. Source data underlying Fig. $4 \mathrm{~d}-\mathrm{i}$ are provided as a Source data file.

tool (BLRT), and an NIR-light activation tool (NRAT), were designed and constructed (Supplementary Fig. 13).

The construction of BLAT and BLRT follows a previously reported strategy ${ }^{38}$. To construct a BLAT, two units were designed and assembled (Fig. 4a): a blue optogenetics unit (BOU) to express light-sensitive protein EL222, and an activation reporter unit to replace the LuxR-binding region with an EL222binding region by overlaping the -35 region ( $E$. coli consensus -35 and -10 regions) of the LuxI promoter ${ }^{38}$. In this BLAT, EL222 can bind to the blue-light-inducible promoter following illumination with blue light, and then induce gene expression by recruiting RNA polymerase. To construct a BLRT, the modified J23119 promoter was converted into a transcriptional repressor by positioning the J23119 box between and partially overlapping the consensus -35 and -10 regions of the constitutive promoter ${ }^{38}$, resulting in an repression reporter unit (Fig. 4b), which was then combined with the blue optogenetics unit (BOU). To construct an NRAT, two units were designed and assembled: a near-infrared light unit to constitutively express the $b p h S, b p h O$, $y h j H, m r k H$ genes, and a near-infrared activation unit with the 
$P_{\text {mrkA }}$ promoter (Fig. 4C). In this NRAT, GTP is converted into cdi-GMP by utilizing the BphS and BphO proteins, and then c-diGMP can be degraded by the $\mathrm{YhjH}$ protein. Finally, the $\mathrm{MrkH}$ protein can bind c-di-GMP to activate the MrkH-dependent $P_{\text {mrka }}$ promoter ${ }^{39}$.

The performances of BLAT, BLRT, and NRAT were evaluated. The abundance of mKate (BLAT) and BFP (NRAT) was increased by 9.3 -fold and 10.5-fold with illumination of $0.8 \mathrm{~W} /$ $\mathrm{cm}^{2}$ blue light (Fig. $4 \mathrm{~d}$ ) and $0.8 \mathrm{~W} / \mathrm{cm}^{2}$ NIR light (Fig. $4 \mathrm{f}$ ), respectively, but the GFP abundance (BLRT) was decreased by 15.2 -fold with illumination with $0.8 \mathrm{~W} / \mathrm{cm}^{2}$ blue light (Fig. $4 \mathrm{e}$ ) compared to the corresponding abundance of the dark condition. The genes of interest (GOIs) of BLAT and NRAT showed an increased abundance, but the abundance of the BLRT GOIs decreased with the increasing illumination time $(0-14 \mathrm{~h})$, intensity $\left(0-0.8 \mathrm{~W} / \mathrm{cm}^{2}\right)$, and pulse $(0-100 \%)$ (Supplementary Figs. $14 \mathrm{~A}-\mathrm{C}, 17 \mathrm{~A}-\mathrm{C}$, and $20 \mathrm{~A}-\mathrm{C})$. Then, the bioimaging in Fig. $4 \mathrm{~g}-\mathrm{i}$ for red, green, blue, and panda with a setup were used to display the spatial specificity of BLAT, BLRT, and NRAT. For the temporal specificity of BLAT, BLRT, and NRAT, the reversible transcription activation in $\beta$-galactosidase or $\beta$-glucuronidase was presented by an ON-OFF-ON or OFF-ON-OFF switch under BLAT, BLRT, or NRAT control, respectively (Supplementary Figs. 15A, B, 18A, B, and 20D).

To further obtain a powerful light-inducible tool, we optimized BLAT, BLRT, and NRAT, respectively. In BLAT, the EL222binding site length and EL222 expression level were modified to control the mKate abundance, and thus the results showed a 23.5fold activation in mKate abundance (Supplementary Fig. 16A-C). In BLRT, a promoter library of the -35 and -10 hexamers was constructed and screened to tune the dynamic range of the bacterial promoters, and thus the results revealed a 53-fold repression in GFP expression of aB (TTGACA/GATAAT) group (Supplementary Fig. 19A, B). In NRAT, the RBS strength of $y h j H$ was optimized to regulate the c-di-GMP levels, and thus the results showed a 28.6-fold increase in BFP abundance (Supplementary Fig. 21A). Additionally, these three optogenetic tools were noninvasive for cell growth under blue or NIR light (Supplementary Fig. 22A-C).

The optogenetic tools could efficiently regulate endogenous bacterial genes. BLAT, BLRT, and NRAT were introduced into $E$. coli JM109 to replace the fluorescent proteins and spatiotemporally control cell division. Compared to the control strain, when BLAT was used to shorten the $\mathrm{C}+\mathrm{D}$ periods of cell division, the SSA was increased by 1.26 -fold (Supplementary Fig. 23A). In addition, when BLAT was used to prolong the $\mathrm{C}$ and $\mathrm{D}$ periods of cell division, the MCV was increased by 3.68 -fold and 10.36-fold, respectively (Supplementary Fig. 23A). Similarly, when BLRT and NRAT were introduced into $E$. coli JM109, the C and D periods of cell division were increased and decreased, respectively (Supplementary Fig. 23B, C). To further confirm the universal properties of these optogenetic tools, BLAT, BLRT, and NRAT were introduced into lactateproducing strain E. coli GL0002 $2^{40}$ and pyruvate-producing strain $E$. coli $\mathrm{F} 0601^{40}$, the similar changes in the $\mathrm{C}$ and $\mathrm{D}$ period of cell division were also detected, respectively (Supplementary Fig. 24A). Together, these results demonstrated that the optogenetic tools exhibited good applicability for the regulation of cell division.

Enhancing acetoin production by shortening cell division. Acetoin, a food flavoring and fragrance, is widely used in the food, pharmaceutical, and chemical industries ${ }^{41}$. An engineered E. coli D1 strain was constructed by constitutively overexpressing $b u d A, b u d B$, and nox genes in the biosynthetic pathway of acetoin. Based on this, the engineered strain produced $13.5 \mathrm{~g} \mathrm{~L}^{-1}$ acetoin (Fig. 5A, D, Supplementary Data 1 and 2).
Then, the state of cell division and robustness of engineered $E$. coli D1 were analyzed. As shown in Fig. 5D and Supplementary Fig. 28B, it was found that the $\mathrm{C}+\mathrm{D}$ period of cell division (E. coli D1) was prolonged by $33.09 \%$ compared to E. coli F0601. As a result, the SSA and relative cell viability of $E$. coli D1 were decreased by $6.89 \%$ and $50.5 \%$, respectively. These results demonstrated that prolonging the $\mathrm{C}+\mathrm{D}$ period of cell division decreased SSA, and then disturbed cell viability, thus leading to the cessation of cell growth and potentially affecting acetoin production. To enhance cell growth and improve strain robustness, the process of acetoin fermentation was divided into three phases by introducing the optogenetic strategies to shorten cell division: (1) shortening phase to shorten cell division and increase the SSA by high-level expression of $n r d A B+f t s Z A$; (2) cooperating phase to balance cell growth and acetoin production by expressing $n r d A B+f t s Z A$ at a moderate level and stimulating the expression of the $r p o S^{42}$; and (3) defensing phase to improve strain robustness by expressing $n r d A B+f t s Z A$ at a moderate level and $r p o S$ at a high level (Fig. 5c, Supplementary Fig. 25A, B, Supplementary Note 3, and Supplementary Data 4).

To spatiotemporally tune these three phases, a blue-light activation and NIR-light activation system (BANA) was constructed by combining BLAT and NRAT (Fig. 5b). Then, we confirmed the similar functions of dose-dependent and spatiotemporal specificity of BANA by implementing the illumination intensity, pulse, bioimaging, and GOIs abundance experiments, respectively (Supplementary Fig. 26A-C). Further, BANA was introduced into $E$. coli $\mathrm{D} 1$ to increase acetoin production by spatiotemporally regulating the expression of $n r d A B$, fts $Z A$, and rpos. Based on this, the aforementioned three phases were achieved by manipulating the intensity and time of blue-light and NIR-light illumination, respectively (Fig. 5c, Supplementary Fig. 27A-C). This manipulation led to the formation of E. coli DN4. As a result, the $\mathrm{C}+\mathrm{D}$ period of $E$. coli $\mathrm{DN} 4$ was shortened by $35.56 \%$ compared to $E$. coli $\mathrm{D} 1$, whereas the SSA, relative cell viability and half-maximal inhibitory concentration were increased by $20.39 \%, 62.18 \%$, and $46.23 \%$, respectively (Fig. 5 d, f, Supplementary Fig. 28A, B). These results led to a $131.1 \%$ increase in the titer and productivity of acetoin in E. coli DN4 compared to those of $E$. coli D1, respectively (Fig. 5d). When this culture was scaled up to a 5-L fermenter, the acetoin titer, productivity, and $\mathrm{OD}_{600}$ of $E$. coli $\mathrm{DN} 4$ under light conditions were increased to $67.2 \mathrm{~g} \mathrm{~L}^{-1}, 0.93 \mathrm{~g} \mathrm{~L}^{-1} \mathrm{~h}^{-1}$, and 64.97 , respectively, which were $39.19,39.19$, and $16.43 \%$ higher than that of $E$. coli $\mathrm{D} 1,15.17,15.17$, and $6.02 \%$ higher than that of E. coli D3, $41.5,41.5$, and $23.78 \%$ higher than that of E. coli DN4 under the dark condition, respectively (Fig. 5e, Table 1). Furthermore, based on the fluorescence intensity and fluorescence density percentage under 5 and $10 \mathrm{~L}$ fermenters, a similar fluorescence expression in $250 \mathrm{~mL}$ shake flasks was activated. These results indicated the fine applicability of scale and high-density fermentation (Supplementary Figs. 31-33, and Supplementary Note 4).

Increasing poly(lactate-co-3-hydroxybutyrate) (PLH) production by prolonging cell division. PLH is a biodegradable and biocompatible synthetic polymer that accumulates as inclusion bodies in microorganisms ${ }^{43}$. We engineered $E$. coli DQ0, in which the phaA, phaB, phaC, and pct genes involved in the PLH pathway were constitutively overexpressed. Analytical result showed that its PLH content was at $11.5 \mathrm{wt} \%$ level (Fig. 6a, d, Supplementary Data 1 and 2). Then, the state of cell division were analyzed (Supplementary Fig. 34A, B). We found that the C+D period of cell division (E. coli DQ0) was prolonged by $17.95 \%$ (Fig. 6d). As a result, the MCV was increased by $9.38 \%$, but c.f.u of E. coli DQ0 was decreased by $8.9 \%$ compared to that of E. coli 
a

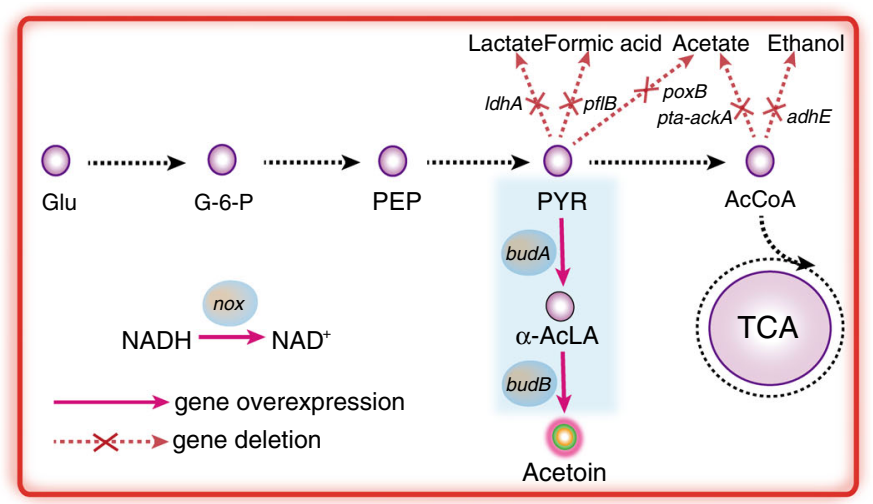

b

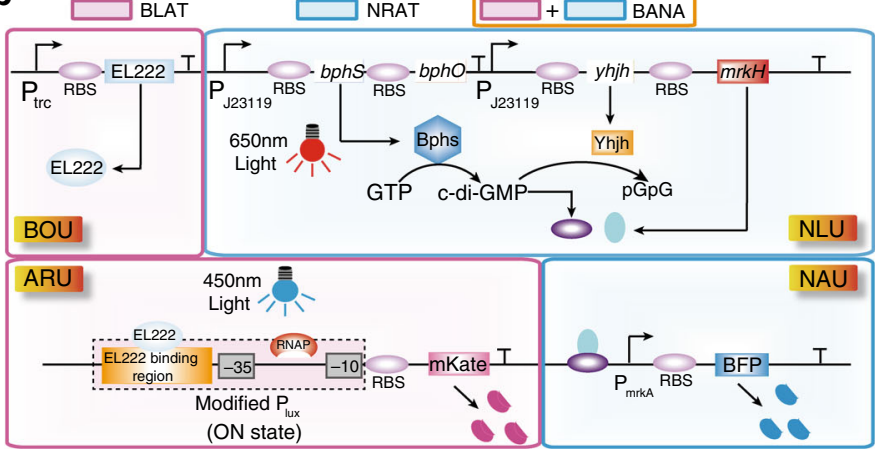

C

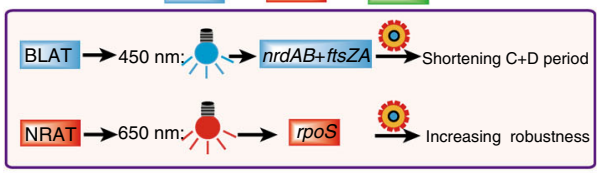

d

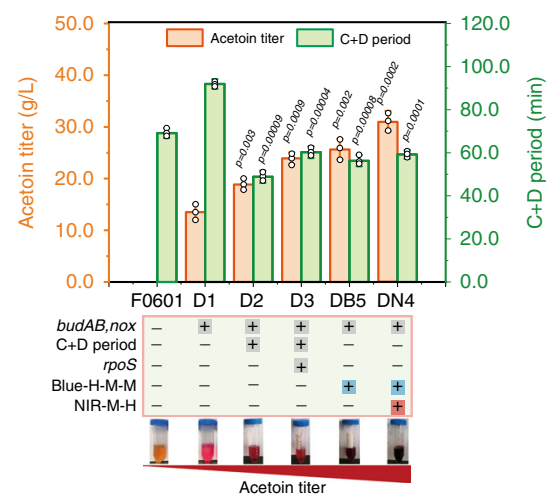

e

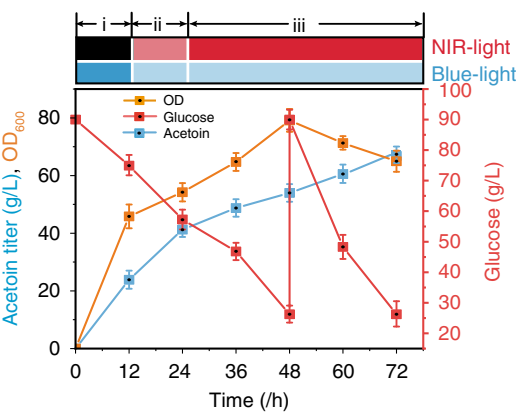

f
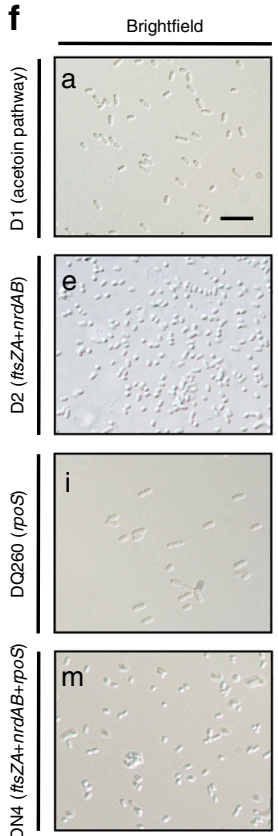

PI staining
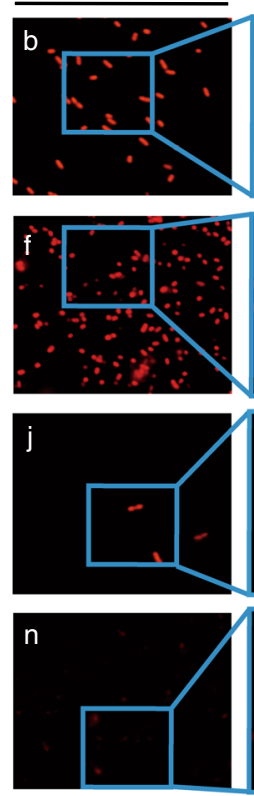
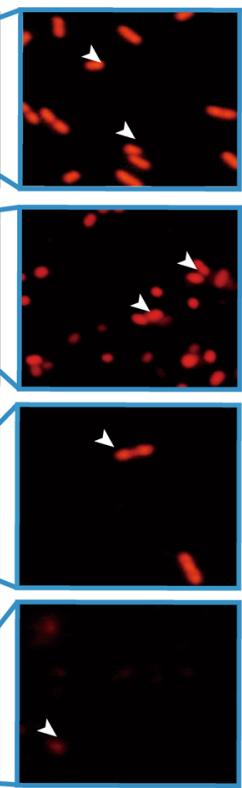

FESEM
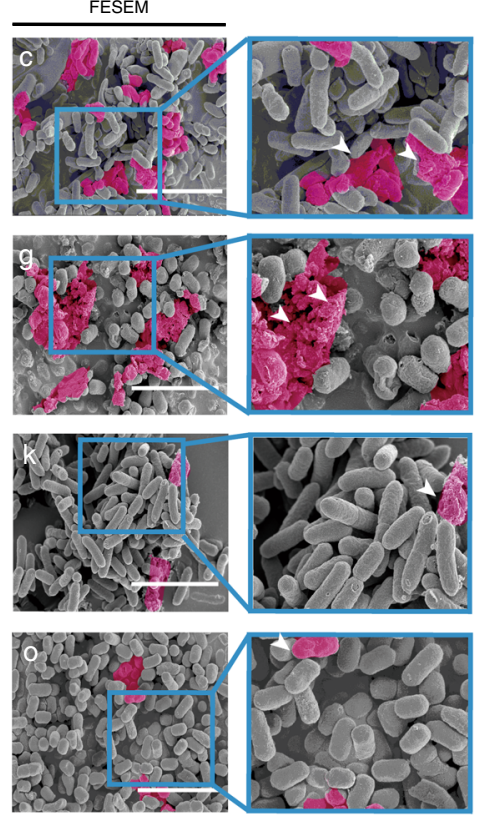
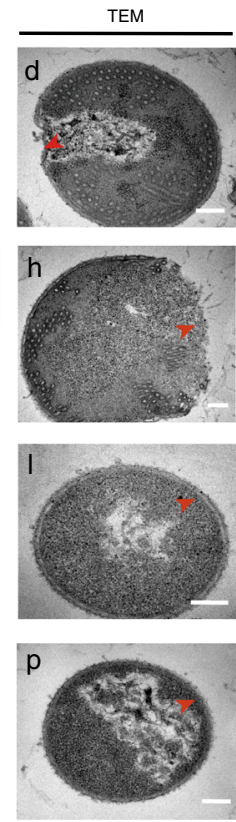

GL0002 (Fig. 6d, Supplementary Fig. 39A, C). These results indicated that PLH production was limited by the MCV and cell counts. To solve these limitations in PLH fermentation, the process of PLH biosynthesis was divided into three phases by introducing the optogenetic strategies to prolong cell division: (1) shortening cell division to increase the cell count by the expression of $\operatorname{nrdAB}, f t s Z A$, and $n r d A$; (2) switching time phase to increase the PLH content by optimizing the switch time from dark to blue light; and (3) prolonging cell division to increase the
MCV by stimulating the expression of sulA and decreasing the expression of $n r d A$ (Fig. 6c, Supplementary Fig. 34A, B).

To spatiotemporally regulate these three phases, a blue light activation-repression and NIR light activation system (BARNA) was constructed by combining BANA and BLRT (Fig. 6b). Then, we confirmed the similar functions of dose-dependent and spatiotemporal specificity of BARNA by conducting the illumination pulse, intensity, bio-imaging, and GOIs abundance experiments (Supplementary Fig. 35A, 36A, B). Furthermore, BARNA 
Fig. 5 Shortening cell division for acetoin production by the BANA system. a The schematic diagram of acetoin biosynthesis pathway in E. coli D1. b The schematic diagram of BANA containing the BLAT and NRAT. c Enhancing acetoin production by BANA regulation. BLAT was used to control nrdAB and $f t s Z A$, and at the same time NRAT controlled rpoS. $\mathbf{d}$ Effect of illumination combination on the $C+D$ periods and acetoin production. $H, M$, and $L$ were 0.8 , 0.3 , and $0.2 \mathrm{~W} / \mathrm{cm}^{2}$, respectively (Supplementary Fig. $27 \mathrm{~A}-\mathrm{C}$ ). The genes in the $\mathrm{C}+\mathrm{D}$ periods of cell division were constitutively expressed in E. coli D1, resulting in $E$. coli $\mathrm{D} 2$. The rpoS gene was constitutively expressed in $E$. coli $\mathrm{D} 2$, resulting in $E$. coli $\mathrm{D} 3$. The genes in the $\mathrm{C}+\mathrm{D}$ periods of cell division were controlled by blue light in E. coli D1, resulting in E. coli DB5 (Blue-H-M-M represented $0.8 \mathrm{~W} / \mathrm{cm}^{2}$ blue-light in phase I and $0.3 \mathrm{~W} / \mathrm{cm}^{2}$ blue-light in phase II and phase III). The rpoS gene was controlled by NIR-light in E. coli DB5, resulting in E. coli DN4 (NIR-M-H represented $0.3 \mathrm{~W} / \mathrm{cm}^{2} \mathrm{NIR}-$ light in phase II and $0.8 \mathrm{~W} / \mathrm{cm}^{2}$ NIR-light in phase III (Supplementary Fig. 30A, B, and Supplementary Note 6). The inserted figure was the creatine color reaction. e Acetoin production with the engineered $E$. coli DN4 controlled by light stimulation during fed-batch fermentation. $\mathbf{f}$ Effect of shortening cell division on cell morphology during acetoin production. The rpoS gene was constitutively expressed in $E$. coli D1, resulting in E. coli DQ260. The scale bar for $\mathrm{c}, \mathrm{g}$, $\mathrm{k}$, o are 5 $\mu \mathrm{m}$. For $\mathrm{d}, \mathrm{h}, \mathrm{l}, \mathrm{p}$ are $0.2 \mu \mathrm{m}$. For a, e, i, $\mathrm{m}$ are $5 \mu \mathrm{m}$. d, e Values are shown as mean \pm s.d. for $n=3$ biological independent replicates. Glu glucose, G6P glucose-6-phosphate, PYR pyruvate, PEP phosphoenolpyruvate, AcCoA acetyl-CoA, $\alpha$-acLA $\alpha$-acetolactate, $\alpha$-ackA acetate kinase A, adhE alcohol dehydrogenase, IdhA lactate dehydrogenase, poxB pyruvate oxidase, pflB pyruvate-formate lyase; pta phosphate acetyl transferase, budA $\alpha$-acetolactate synthase, budB $\alpha$-acetolactate decarboxylase, nox NADH oxidase. Significance ( $p$-value) was evaluated by two-sided $t$-test, compared to $E$. coli D1. Source data underlying Fig. $5 \mathrm{~d}-\mathrm{f}$ are provided as a Source data file.

Table 1 Differences in wild type and morphology engineered $E$. coli on production of acetoin in $5 \mathrm{~L}$ fermenter.

\begin{tabular}{|c|c|c|c|c|}
\hline Chemical & Strains characteristics & Titer $\left(\mathrm{g} \mathrm{L}^{-1}\right)$ & Productivity $\left(\mathrm{g} \mathrm{L}^{-1} \mathrm{~h}^{-1}\right)$ & Cell growth $\left(O D_{600}\right)$ \\
\hline \multirow[t]{4}{*}{ Acetoin } & E. coli D1 (Acetoin pathway) & 48.28 & 0.67 & 55.8 \\
\hline & E. coli D3 (Acetoin pathway $+\mathrm{C}$ and D period, rpoS) & $58.35(p=0.019)$ & $0.81(p=0.019)$ & $61.28(p=0.05)$ \\
\hline & $\begin{array}{l}\text { E. coli DN4 in the dark condition (Acetoin pathway + BANA- } \\
\text { controlled C and D period, rpoS) }\end{array}$ & 47.49 & 0.66 & 52.49 \\
\hline & $\begin{array}{l}\text { E. coli DN4 in the light condition (Acetoin pathway + BANA- } \\
\text { controlled C and D period, rpoS) }\end{array}$ & $67.2(p=0.011)$ & $0.93(p=0.011)$ & $64.97(p=0.022)$ \\
\hline
\end{tabular}

was introduced into E. coli DQ0 to enhance PLH production by spatiotemporally controlling the expression of $\operatorname{nrdAB}$, fts $Z A$, $n r d A$, and sulA genes. Based on this, the aforementioned three phases were achieved by adjusting the illumination intensity and time (Fig. 6c, Supplementary Fig. 37A, B, and Supplementary $38 \mathrm{~A}, \mathrm{~B})$. This manipulation led to the formation of E. coli DQ8. As a result, compared to E. coli DQ0, the $\mathrm{C}+\mathrm{D}$ period of $E$. coli DQ8 was prolonged by 1.96-fold, whereas the cell wall thickness was decreased by $18.6 \%$ (Fig. $6 \mathrm{D}, \mathrm{F}$ ). In addition, the MCV and c.f.u were increased by 13.65 -fold and 1.16 -fold, respectively (Supplementary Fig. 39A, C). These results led to the PLH content, DCW, and PLH titer increased to $38.5 \mathrm{wt} \%, 7.41 \mathrm{~g} \mathrm{~L}^{-1}$, and $2.85 \mathrm{~g} \mathrm{~L}^{-1}$, respectively, which was $234.78,36.96,359.68 \%$ higher than that of E. coli DQ0 (Fig. 6d, f, Supplementary Fig. 39B). After that, the switch time in the dark was optimized before starting fermentation, and the PLH content was increased to $47.5 \mathrm{wt} \%$ (Supplementary Fig. 39D). When this culture were scaled up to $5 \mathrm{~L}$ fermenter, the PLH titer, content, and DCW of $E$. coli DQ8 under the light condition were $14.31 \mathrm{~g} \mathrm{~L}^{-1}, 53.8 \mathrm{wt} \%$, and $26.6 \mathrm{~g} \mathrm{~L}^{-1}$, which were $137.71,100.97$, and $18.33 \%$ higher than that of E. coli DQ0, 34.87, 22.66, and 9.96\% higher than that of $E$. coli DQ280, 114.22, 86.87, and 14.61\% higher than that of $E$. coli DQ8 under the dark condition, respectively (Fig. 6e, Table 2).

\section{Discussion}

In this study, the BANA and BARNA light-powered systems were constructed and employed to spatiotemporally regulate the cell division of E. coli. When the BANA light-powered system was used to shorten cell division of E. coli DN4, the SSA and acetoin titer of E. coli DN4 were increased to $3.7 \mu \mathrm{m}^{-1}$ and $67.2 \mathrm{~g} \mathrm{~L}^{-1}$, which were 20.39 and $39.19 \%$ higher than these of E. coli D1, respectively. When the BARNA light-powered system was used to prolong the cell division of E. coli DQ8, the MCV, PLH content, DCW, and PLH titer of E. coli DQ8 were increased to $52.6 \mu^{3}$, $53.8 \mathrm{wt} \%, 26.6$ and $14.31 \mathrm{~g} \mathrm{~L}^{-1}$, which were 13.65 -fold, 2.01 -fold, 1.18-fold, and 2.38-fold higher than these of E. coli DQ0, respectively. These results demonstrated that engineering the $\mathrm{C}$ and $\mathrm{D}$ periods of cell division represented an useful strategy to streamline the efficiency of microbial cell factories.

Cell division in Escherichia coli is mediated by a large protein complex and deoxyribonucleotides ${ }^{31,37}$, which are regulated by two factors: (i) a positive regulator: the $\operatorname{nrdAB}, n r d A, n r d B$, and $n r d D$ genes in the $C$ period of cell division catalyze deoxyribonucleoside diphosphate for dNTP production to promote DNA replication for cell division, and then the fts $Z A, f t s Z$, fts $A, f t s N$, and $f t s Q$ genes in the $\mathrm{D}$ period of cell division assemble into a Z-ring scaffold to accelerate cell division; (ii) a negative regulator: the deletion of the $n r d A B, n r d A, n r d B$, and $n r d D$ genes in the $C$ period of cell division can perturb dNTP synthesis, and then the $\operatorname{sul} A, \min C, \min D, \min E$, and $f t s H$ genes in the $\mathrm{D}$ period of cell division are the inhibitors of cell division. To regulate cell division at multiple levels, optogenetics is a promising strategy in a noninvasive, reversible, and spatiotemporal way ${ }^{33}$. For example, a blue light feedback gene circuit was used to reversibly regulate pyruvate decarboxylation to decouple cell growth and chemical production, resulting in isobutanol and 2-methyl-1-butanol production up to $8.49 \mathrm{~g} \mathrm{~L}^{-1}$ and $2.38 \mathrm{~g} \mathrm{~L}^{-1}$, respectively ${ }^{33}$. In addition, red light and blue light were utilized to regulate the Bphs and BlrP1 proteins for biofilm formation ${ }^{44}$. Based on these studies, an optogenetics-based cell division strategy was proposed: the optogenetic strategy was used to shorten or prolong the $\mathrm{C}+\mathrm{D}$ period of cell division by spatiotemporally controlling the genes involved in the $\mathrm{C}+\mathrm{D}$ periods of cell division in different phases with various light illumination intensities and times. Thus, two different light-powered systems, BANA and BARNA, were constructed. A BARNA light-powered system was used for weak expression of $n r d A$ and overexpression of $n r d A B, f t s Z A$, and sulA in E. coli DQ8, and thus the C and D periods of cell division were prolonged. As a result, this system causes the mini-cell phenotype ${ }^{29}$ and increases the cell count and cell growth ${ }^{30,45}$. To hinder DNA replication and decrease cell division frequency, a BARNA light-powered system was used for 
a

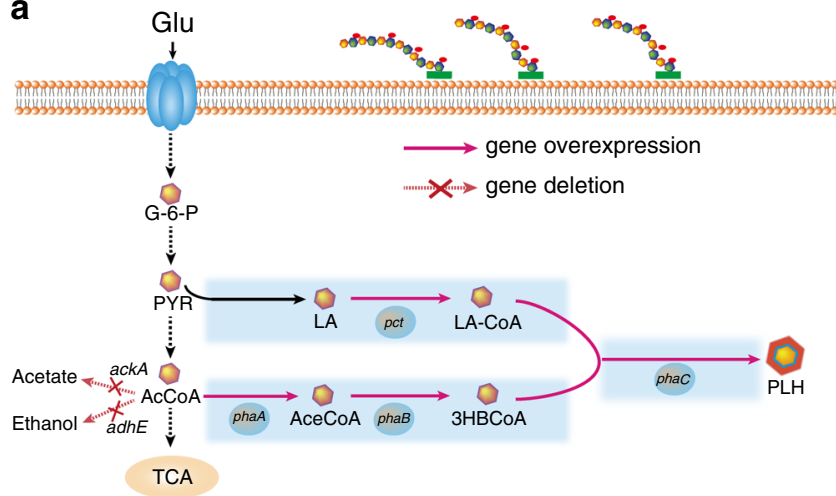

P.

b

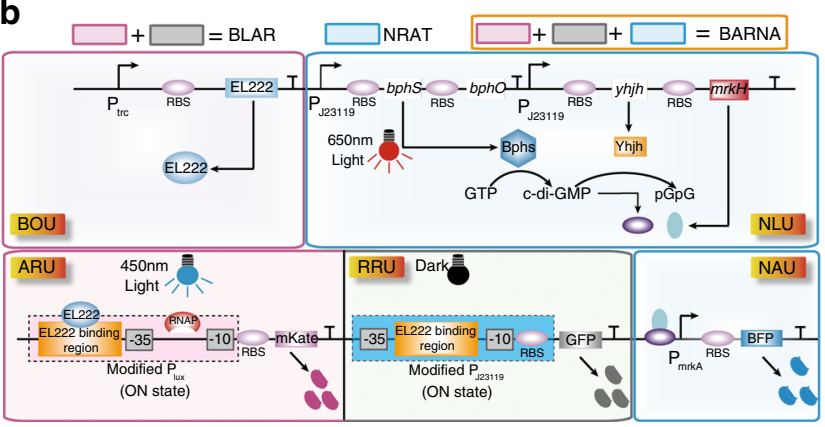

C

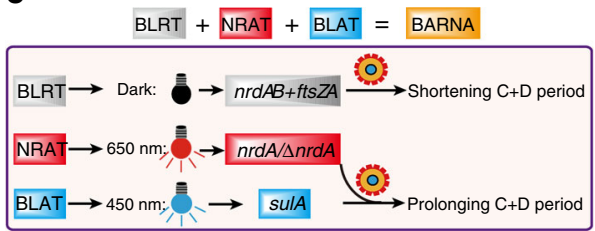

d

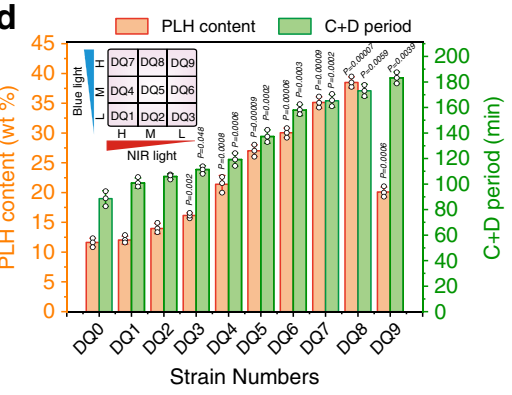

e

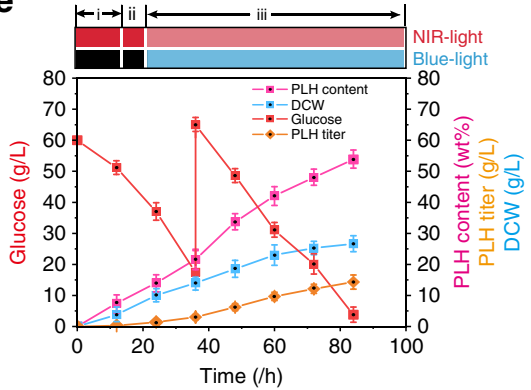

f
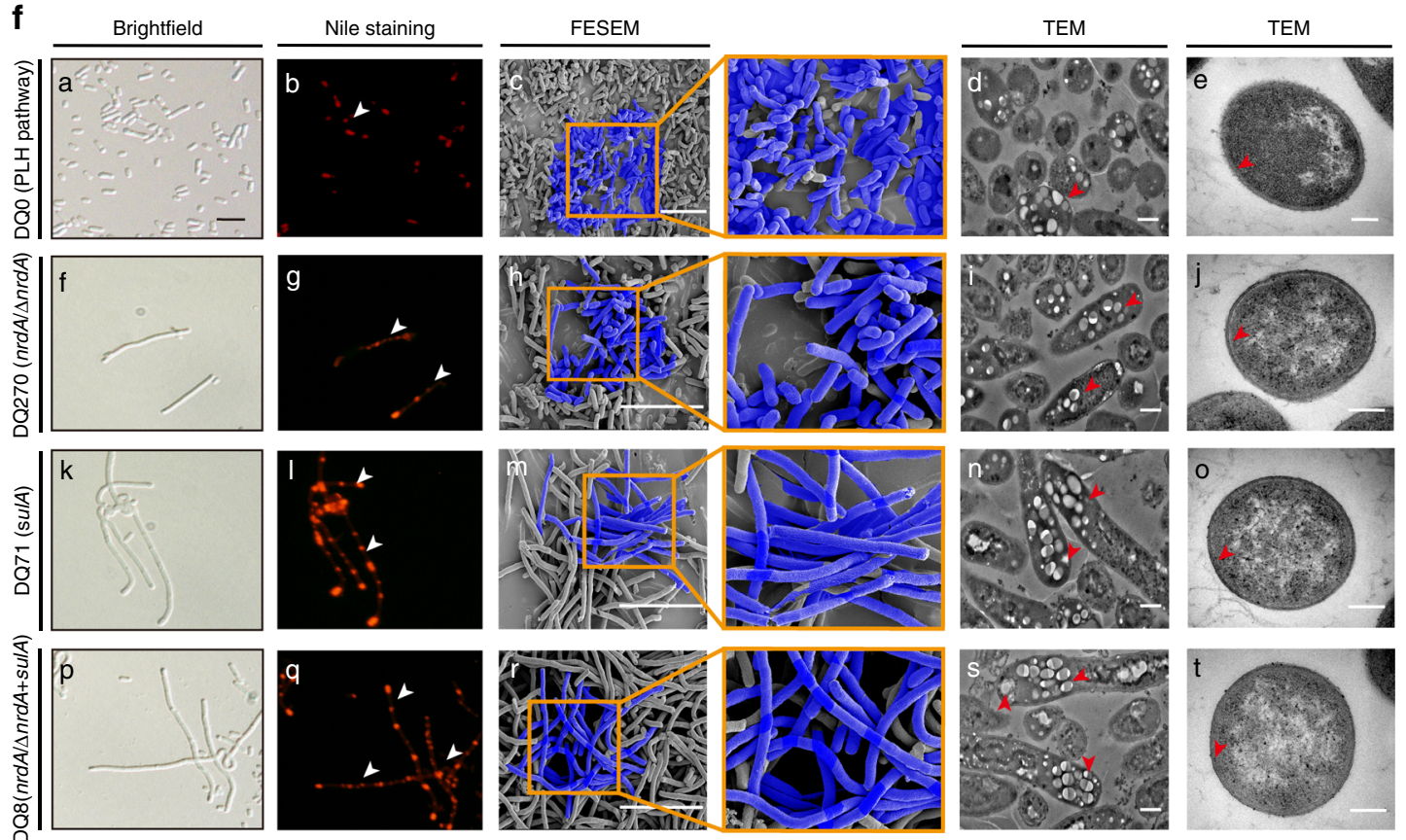

weak expression of $n r d A$ and overexpression of $n r d A B$, ftsZA, and sulA in E. coli DQ8, and thus the $\mathrm{C}$ and $\mathrm{D}$ periods of cell division was prolonged. Thus, this system causes a large-cell phenotype and decreases cell count and cell growth ${ }^{13,46}$.

As a vital physiological parameter of industrial microbes ${ }^{20,47}$, SSA could increase mass transfer by enhancing the nutrient uptake rate and cell growth and improve cell density by changing the rheology of cultures. During industrial fermentation, SSA can be affected by mechanical pressure, medium contents, and chemical stress ${ }^{16}$. Thus, many efforts have showed their application potential in regulating SSA, such as microparticle cultivation ${ }^{20}$, fermentation optimization ${ }^{48}$, and laboratory adaptive evolution engineering ${ }^{49}$. Based on these strategies, the efficiency of chemical production will be enhanced by increasing the SSA of industrial microbes. In this study, when the $\mathrm{C}$ and $\mathrm{D}$ periods of cell division were shortened by BANA, the SSA was showed a $20.39 \%$ increase. As a result, the acetoin titer was increased by $39.19 \%$ compared to that of E. coli D1. These results indicated that acetoin production was improved by accurately controlling cell division and engineering SSA. This study was different from the previous studies 
Fig. 6 Prolonging cell division for PLH production by the BARNA system. a The schematic diagram of PLH biosynthesis pathway in E. coli DQO. b The schematic diagram of BARNA containing BLRT and BANA. c Increasing PLH production by BARNA regulation. BLRT, BLAT, and NRAT were used to control $n r d A B+f t s Z A$, sul $A$, and $n r d A$, respectively. d Effect of blue-light and NIR-light combination on PLH content and the $C+D$ periods. $H, M$, and $L$ were 0.8 , 0.3 , and $0.2 \mathrm{~W} / \mathrm{cm}^{2}$, respectively (Supplementary Figs. 37A, B, 38A, B). The inserted figure was nine combination group (E. coli DQ1-DQ9) with orthogonally matrix by blue and NIR-light illumination intensity. e PLH production with the engineered $E$. coli DQ8 controlled by light stimulation during fedbatch fermentation. Phase I, II, and III were controlled by $0.8 \mathrm{~W} / \mathrm{cm}^{2} \mathrm{NIR}-$ light, $0.8 \mathrm{~W} / \mathrm{cm}^{2} \mathrm{NIR}-$ light, $0.8 \mathrm{~W} / \mathrm{cm}^{2}$ blue-light and $0.3 \mathrm{~W} / \mathrm{cm}^{2} \mathrm{NIR}-$ light, respectively. $\mathbf{f}$ Effect of prolonging cell division on cell morphology during PLH production. The $n r d A$ and sulA genes were constitutively expressed in $E$. coli DQ0, resulting in E. coli DQ270 and E. coli DQ271, respectively. The scale bar for $c, h, m, r$ is $10 \mu \mathrm{m}$. The scale bar for $d, i, n$, and $s$ is $0.5 \mu \mathrm{m}$. For $\mathrm{e}, \mathrm{j}, \mathrm{o}$, and $\mathrm{t}$ is $0.2 \mu \mathrm{m}$. For $a, f, k$, and $p$ is $5 \mu \mathrm{m}$. $\mathbf{d}$, e values are shown as mean \pm s.d. from three $(n=3)$ biological independent replicates. Glu glucose, G6P glucose 6 phosphate, PYR pyruvate, LA lactate, PEP phosphoenolpyruvate, AcCoA acetyl-CoA, aceCoA acetoacetyl-CoA, 3HBCoA 3-hydroxybutyryl-CoA, LAcoA lactyl-coA, ackA acetate kinase $\mathrm{A}$, adhE alcohol dehydrogenase, phaA $\beta$-ketothiolase, phaB acetoacetyl-CoA reductase, phaC PHA synthase, pct propionylCoA transferase. Significance ( $p$-value) was evaluated by two-sided $t$-test, compared to E. coli DQO. Source data underlying Fig. $6 \mathrm{~d}-\mathrm{f}$ are provided as a Source data file.

Table 2 Differences in wild type and engineered $E$. coli on PLH production in $5 \mathrm{~L}$ fermenter.

\begin{tabular}{|c|c|c|c|c|c|}
\hline Chemical & Strains characteristics & $\begin{array}{l}\text { PLH contents } \\
\text { (wt\%) }\end{array}$ & Titer $\left(\mathbf{g ~ L}^{-1}\right)$ & $\begin{array}{l}\text { Productivity } \\
\left(\mathrm{g} \mathrm{L}^{-1} \mathrm{~h}^{-1}\right)\end{array}$ & DCW $\left(g^{-1}\right)$ \\
\hline \multirow[t]{3}{*}{ PLH } & E. coli DQO (PLH pathway) & 26.77 & 6.02 & 0.07 & 22.48 \\
\hline & E. coli DQ280 (PLH pathway + C and D period) & $43.86(p=0.011)$ & $10.61(p=0.012)$ & $0.13(p=0.012)$ & $24.19(p=0.204)$ \\
\hline & $\begin{array}{l}\text { E. coli DQ8 in the light condition (PLH pathway }+ \\
\text { BARNA-controlled C and D period, light) }\end{array}$ & $53.8(p=0.003)$ & $14.31(p=0.001)$ & $0.17(p=0.001)$ & $26.6(p=0.007)$ \\
\hline
\end{tabular}

that engineered target metabolic pathways ${ }^{41}$ and eliminated carbon catabolite repression ${ }^{50}$.

The MCV of industrial microbes is an important physiological parameter $^{51}$, where we want to maximize inclusion body production. In addition, MCV should be also considered to improve the efficiency of upstream and downstream bioprocessing through faster precipitation of cells with relatively higher gravity. To manipulate the MCV of industrial microbes, a series of strategies have been developed such as perturbing the peptidoglycan cell wall synthesis to obtain a more elastic and flexible cell structure $^{24}$, screening the cytoskeletal mutants for morphological properties $^{25}$, and disturbing the phosphatidylinositol biosynthesis in vivo for the formation of filamentous structures ${ }^{23}$. In this study, when the $\mathrm{C}$ and $\mathrm{D}$ periods of cell division were prolonged by BARNA light-powered systems, the MCV of E. coli DQ8 was showed a 13.65-fold increase. As a result, the cell space for PLH accumulation was increased, and thus the PLH content of E. coli DQ8 was increased by 2.01-fold compared to that of E. coli DQ0. These results indicated the PLH production was improved by accurately regulating the $\mathrm{C}$ and $\mathrm{D}$ periods of cell division to increase the MCV of E. coli DQ8. Weak expression of $n r d A$ could prolong the $\mathrm{C}$ period of cell division by disturbing intracellular dNTP synthesis and DNA replication, and overexpression of sulA could prolong the $\mathrm{D}$ period of cell division by hindering $\mathrm{Z}$ ring formation and divisome assembly ${ }^{46}$. Thus, the frequency of cell division would be affected by prolonging cell division ${ }^{29}$, leading to an increase in cell size. The larger cell space for PLH accumulation improved the PLH content, titer, and DCW. The strategy in this study was different from the previous strategies, such as engineering the target metabolic pathways ${ }^{52}$, utilizing the post translational metabolic switching ${ }^{53}$, and controlling the cofactor ratio ${ }^{54}$.

In this study, an optogenetics-based cell division strategy was developed, which is noninvasive and incorporates spatial, temporal and reversible control. The SSA and MCV of E. coli were increased by shorting or prolonging the $\mathrm{C}$ and $\mathrm{D}$ periods of cell division using a BANA or BRANA light-powered system, respectively. Based on this, the higher SSA or MCV values led to the higher efficiency of acetoin or PLH production. Our results demonstrated that increasing the SSA and MCV by manipulating cell division could enhance the targeted chemical production. Furthermore, this optogenetic-based cell division strategy may provide an approach to construct microbial cell factories for highvalue chemical production.

\section{Methods}

Strains and culture conditions. All plasmids and bacterial strains used in this study were listed in Supplementary Data 1 and 2. Luria-Bertani (LB) broth and plates were used for strain selection and propagation. Kanamycin $\left(50 \mathrm{mg} \mathrm{L}^{-1}\right)$, ampicillin $\left(100 \mathrm{mg} \mathrm{L}^{-1}\right)$, spectinomycin $\left(30 \mathrm{mg} \mathrm{L}^{-1}\right)$, anhydrous tetracycline $(200$ $\left.\mathrm{ng} \mathrm{mL} \mathrm{m}^{-1}\right)$, IPTG $(100-500 \mu \mathrm{M})$ was added appropriately according to different conditions. The key gene targets of cell division were screened using IPTG. For constructing E. coli DQ280, the $\operatorname{nrdAB}$, ftsZA, and sulA were constitutively expressed by promoter $P_{\mathrm{I} 23119}$, and $n r d A$ was expressed by weak promoter $P_{\mathrm{J} 23113}$ with weak RBS B0033. The expression of $n r d A B, n r d A$, $n r d B$, and $n r d D$ in the corresponding gene deletion mutants were controlled by low concentration of IPTG $(10 \mu \mathrm{M})$ and low copy plasmid. The effect of IPTG concentration on gene expression was added in Supplementary Note 5.

For acetoin production, seed cultures were used for fermentation by transferring fresh colonies to a $30 \mathrm{~mL}$ tube containing $5 \mathrm{~mL} \mathrm{LB}$ medium. After culturing for $10 \mathrm{~h}$ at $37^{\circ} \mathrm{C}$ and $200 \mathrm{rpm}$, this fermentation solution was inoculated into a $250 \mathrm{~mL}$ flask with $50 \mathrm{~mL}$ fermentation medium ${ }^{55}\left(100 \mathrm{~g} \mathrm{~L}^{-1}\right.$ glucose, $15 \mathrm{~g} \mathrm{~L}^{-1}$ tryptone, $15 \mathrm{~g} \mathrm{~L}^{-1}$ yeast extract, $3 \mathrm{~g} \mathrm{~L}^{-1} \mathrm{KH}_{2} \mathrm{PO}_{4}$, and $3 \mathrm{~g} \mathrm{~L}^{-1} \mathrm{~K}_{2} \mathrm{HPO}_{4}$, and $0.4 \mathrm{~g} \mathrm{~L}^{-1} \mathrm{MgSO}_{4}$ ) with an initial optical density at $600 \mathrm{~nm}\left(\mathrm{OD}_{600}\right)$ of 0.1 , and then $10 \mathrm{~g} \mathrm{~L}^{-1} \mathrm{CaCO}_{3}$ was added as an acid neutralizing agent. For fed-batch cultures in a $5 \mathrm{~L}$ fermenter (Shanghai Baoxing Biological Engineering Equipment Co. LTD), seed cultures were used for fermentation by transferring fresh colonies to a $250 \mathrm{~mL}$ flask containing $50 \mathrm{~mL} \mathrm{LB}$ medium. Acetoin fermentation was carried out in a $5 \mathrm{~L}$ fermenter containing $3 \mathrm{~L}$ fermentation medium with $5 \%$ inoculum size and $90 \mathrm{~g} \mathrm{~L}^{-1}$ initial glucose, and then supplied with $800 \mathrm{~g} \mathrm{~L}^{-1}$ glucose at $48 \mathrm{~h}$. Acetoin fermentation was maintained at $\mathrm{pH} 6.0$, rotate rate $400 \mathrm{rpm}$, air flow $0.5 \mathrm{vvm}$, and $35^{\circ} \mathrm{C}$ by the automatic addition of $4 \mathrm{M} \mathrm{NaOH}$ or $2 \mathrm{M} \mathrm{HCl}$.

For PLH production, seed cultures were used for fermentation by transferring fresh colonies to a $30 \mathrm{~mL}$ tube containing $5 \mathrm{~mL}$ LB medium. After culturing for 10 $\mathrm{h}$ at $37^{\circ} \mathrm{C}$ and $200 \mathrm{rpm}$, this fermentation solution was inoculated into a $250 \mathrm{~mL}$ flask with $50 \mathrm{~mL}$ MR medium ${ }^{56}\left(60 \mathrm{~g} \mathrm{~L}^{-1}\right.$ glucose, $6.75 \mathrm{~g} \mathrm{~L}^{-1} \mathrm{KH}_{2} \mathrm{PO}_{4}, 2 \mathrm{~g} \mathrm{~L}^{-1}$ $\left(\mathrm{NH}_{4}\right)_{2} \mathrm{HPO}_{4}, 0.85 \mathrm{~g} \mathrm{~L}^{-1}$ citric acid, $3 \mathrm{~g} \mathrm{~L}^{-1}$ yeast extract, $10 \mathrm{~mL}$ trace metal solution per liter; $\mathrm{pH}$ 6.8), with an initial $\mathrm{OD}_{600}$ of 0.1 , and then $10 \mathrm{~g} \mathrm{~L}^{-1} \mathrm{CaCO}_{3}$ was added as an acid neutralizing agent. The composition of the trace metal solution was $10 \mathrm{~g} \mathrm{~L}^{-1} \mathrm{FeSO}_{4} \cdot 7 \mathrm{H}_{2} \mathrm{O}, 2.2 \mathrm{~g} \mathrm{~L}^{-1} \mathrm{ZnSO}_{4} \cdot 7 \mathrm{H}_{2} \mathrm{O}, 0.58 \mathrm{~g} \mathrm{~L}^{-1}$ 
$\mathrm{MnSO}_{4} \cdot 4 \mathrm{H}_{2} \mathrm{O}, 1 \mathrm{~g} \mathrm{~L}^{-1} \mathrm{CuSO}_{4} \cdot 5 \mathrm{H}_{2} \mathrm{O}, 0.1 \mathrm{~g} \mathrm{~L}^{-1}\left(\mathrm{NH}_{4}\right)_{6} \mathrm{Mo}_{7} \mathrm{O}_{24} \cdot 4 \mathrm{H}_{2} \mathrm{O}, 0.2 \mathrm{~g} \mathrm{~L}^{-1}$ $\mathrm{Na}_{2} \mathrm{~B}_{4} \mathrm{O}_{7} \cdot 10 \mathrm{H}_{2} \mathrm{O}$ and $10 \mathrm{~mL}$ of $35 \% \mathrm{HCl}$ per liter. For fed-batch cultures in a $5 \mathrm{~L}$ fermenter (Shanghai Baoxing Biological Engineering Equipment Co. LTD), seed cultures were used for fermentation by transferring fresh colonies to a $250 \mathrm{~mL}$ flask containing $50 \mathrm{~mL} \mathrm{LB}$ medium. PLH fermentation was carried out in a $5 \mathrm{~L}$ fermenter containing $3 \mathrm{~L}$ fermentation medium with $5 \%$ inoculum size and $60 \mathrm{~g} \mathrm{~L}^{-1}$ initial glucose, and then supplied with $800 \mathrm{~g} \mathrm{~L}^{-1}$ glucose at $36 \mathrm{~h}$. PLH fermentation was maintained at $\mathrm{pH} 6.5$, rotate rate $500 \mathrm{rpm}$, air flow $1 \mathrm{vvm}$ and $37^{\circ} \mathrm{C}$ by the automatic addition of $4 \mathrm{M} \mathrm{NaOH}$ or $2 \mathrm{M} \mathrm{HCl}$. Cell density was measured at $600 \mathrm{~nm}$ by a spectrophotometer.

Optogenetics working conditions. For optogenetics LED illustration, cells were illuminated using a custom built $300 \mathrm{~mm} \times 300 \mathrm{~mm} \times 50 \mathrm{~mm}$ LED blue light and NIR light panels with adjustable ON/OFF pulsing and intensity. Two $450 \mathrm{~nm}$ blue light or two $650 \mathrm{~nm}$ NIR light (The characteristic of LED panel is $22 \mathrm{~W}, 24 \mathrm{~V}, 1.7$ A; MODEL: HF-FX160, square light source) were opened to illuminate fermenter for activating gene expression. Light panel was placed $5 \mathrm{~cm}$ away from the vessel walls. These equipments were purchased from KOMA Vision Technology Company and LEMONS Co., Ltd, CHINA. Switching power supply AC/DC ADAPTER (MODEL: SPF-1210) was used to power the lighting apparatus simultaneously (AC $100-240 \mathrm{~V} \sim 50 / 60 \mathrm{~Hz}$; OUTPUT: DC $12 \mathrm{~V}, 10 \mathrm{~A}$ ). For improving the applicability and stability of scale, fermentation process was adopted a wrap-round illumination-type by two blue light and two NIR light illumination sources to surround $5 \mathrm{~L}$ and $10 \mathrm{~L}$ fermenters, respectively.

For optogenetics-controlled mKate and BFP expression in $5 \mathrm{~L}$ fermenter and $10 \mathrm{~L}$ fermenters (Labfors 5 Bacteria, INFORS, Switzerland), the culture $\mathrm{pH}$, air flow, temperature were kept at $6.0,1 \mathrm{vvm}$, and $37^{\circ} \mathrm{C}$, respectively. Samples were taken for every $12 \mathrm{~h}$ to measure $\mathrm{OD}_{600}$ and $\mathrm{DCW}$ of cell cultures. The average measurements were measured with three independent fermentation and the error bars were corresponded to the standard deviations of those three measurements. To analyze the expression of fluorescence proteins, fermentation was carried out in a $10 \mathrm{~L}$ fermenter containing $7.5 \mathrm{~L}$ fermentation medium with $5 \%$ inoculum size, and then supplied with $100 \mathrm{~g} \mathrm{~L}^{-1}$ yeast extract, $25 \mathrm{~g} \mathrm{~L}^{-1}$ peptone, and $400 \mathrm{~g} \mathrm{~L}^{-1}$ glycerol at a rate of $16 \mathrm{~mL} \mathrm{~h}^{-1}$ for high density fermentation. When cells density was increased to an $\mathrm{OD}_{600}$ of 10 in $5 \mathrm{~L}$ and $10 \mathrm{~L}$ fermenters, blue light or NIR light sources was opened to activate the expression of fluorescence proteins.

DNA manipulation and plasmid construction. Gene deletions were performed according to the Red homologous recombination method ${ }^{40}$. All plasmids were constructed using basic molecular cloning techniques and Gibson assembly. To construct the acetoin biosynthesis pathway, the $b u d A$ and $b u d B$ genes were amplified by PCR from genomic DNA of S. marcescens H30. Similarly, the nox gene from L. breris was synthesized by Suzhou Genewiz Biotechnology with codon optimization. For constructing the PLH biosynthesis pathway, the pct gene from $M$. elsdenii, phaA and phaB genes from R. eutropha, and phaC gene from Pseudomonas sp. were synthesized by Suzhou Genewiz Biotechnology with codon optimization. The el222, bphS, bphO,yhjH, mrkH genes were synthesized by Suzhou Genewiz Biotechnology with codon optimization. Supplementary Data 2 and 3, gives a list of the relevant parts, sequences, and sources. Primers used in this study were listed in Supplementary Table 1.

BANA and BARNA implementation. BANA and BARNA system were constructed. In short, the BANA and BARNA were implemented with a two-plasmid system, respectively. Supplementary Data 1-3 showed the names and sequences of BANA and BARNA. In BANA, two plasmids, $\mathrm{P}_{\mathrm{Trc}}-\mathrm{E}-\mathrm{P}_{\mathrm{I} 23119}-\mathrm{SO}-\mathrm{P}_{\mathrm{J} 23119}-\mathrm{Y}_{30} \mathrm{M}$, and pBLind-v1- $\mathrm{P}_{\text {mrkA }}-\mathrm{BFP}$, were used as input plasmids with various blue-light and NIR-light illumination. In BARNA, two plasmids, $\mathrm{P}_{\mathrm{Trc}}-\mathrm{E}-\mathrm{P}_{\mathrm{J} 23119}-\mathrm{SO}-\mathrm{P}_{\mathrm{J} 23119}-\mathrm{Y}_{30} \mathrm{M}$ and $\mathrm{pBLirnd}-\mathrm{v} 1-\mathrm{P}_{\mathrm{mrkA}}-\mathrm{BFP}$, were used as input plasmids with various blue-light and NIR-light illumination.

To test BANA, a colony of BANA cells containing a controller plasmid $\mathrm{P}_{\text {Trc }}-\mathrm{E}-$ $\mathrm{P}_{\mathrm{J} 23119}-\mathrm{SO}-\mathrm{P}_{\mathrm{J} 23119}-\mathrm{Y}_{30} \mathrm{M}$ and an actuator plasmid $\mathrm{pBLind}-\mathrm{v} 1-\mathrm{P}_{\text {mrkA }}-\mathrm{BFP}$ was inoculated into medium with the corresponding ampicillin and spectinomycin for overnight $(12-14 \mathrm{~h})$ at $37^{\circ} \mathrm{C}$. Then, seed cultures were inoculated in the refresh LB for $12-14 \mathrm{~h}$ under the different blue-light $(450 \mathrm{~nm})$ or NIR-light $(650 \mathrm{~nm})$ illumination. This experiment was repeated with a different starting colony for three biological replicate. All cultures were grown in $50 \mathrm{~mL}$ medium in $250 \mathrm{~mL}$ shake flasks at $200 \mathrm{rpm}$. Finally, fluorescence density was analyzed (see below). To test BARNA, its method was similar to that of BANA.

Analytical methods. The $\mathrm{OD}_{600}$ was measured using a spectrophotometer. Glucose analysis was quantified by the biosensor SBA-90E biological sensor. Acetoin were determined by high-performance liquid chromatography using an Aminex HPX-87H column $(7.8 \times 300 \mathrm{~mm}$; Bio-Rad Laboratories, Inc., Hercules, CA, USA) at $60{ }^{\circ} \mathrm{C}$ with $0.05 \mathrm{mM}$ sulfuric acid as the mobile phase. The injection volume was $20 \mu \mathrm{L}$, and the flow rate was $0.6 \mathrm{~mL} \mathrm{~min}^{-1}$. Bacterial cells were harvested by centrifugation at $8000 \mathrm{r} \mathrm{min}^{-1}$ for $10 \mathrm{~min}$. The supernatant was discarded, and then cells were washed twice with $20 \mathrm{~mL}$ distilled water. Dry cell weight (DCW) was assayed after vacuum lyophilization. PLH contents were quantitatively analyzed by gas chromatography (GC-2014, SHIMADZU, Japan) after methanolysis of lyophilized cells in chloroform. Analytical P3HB and P(GA-LA) purchased from Sigma-Aldrich were used as analysis standards.

The parameters of $\boldsymbol{E}$. coli morphology. The model of $E$. coli was showed in Supplementary Fig. 40, which was used to calculate the mean cell width and MCL The mean cell width was calculated from cell midline to cell midline. The MCL was calculated from pole to pole. The parameters ${ }^{25}$ of $E$. coli morphology were used to segment cells and to identify cell outlines from Nikon eclipse 80i microscope (Nikon corporation) image for 100 individuals cell. Specific surface area was calculated by dividing $S(1)$ by $V(2)$.

$$
\begin{gathered}
S=2 \pi R(L-2 R)+4 \pi R^{2}, \\
V=\pi R^{2}(L-2 R)+4 / 3 \pi R^{3},
\end{gathered}
$$

where $R$ is the mean cell width and $L$ is the MCL, $V$ is cell volume, and $S$ is surface area.

Assay of field emission scanning electron microscope (FESEM) and transmission electron microscopy (TEM). Bacterial cells were collected by centrifugation at $1500 \mathrm{r} \mathrm{min}^{-1}$ for $2 \mathrm{~min}$, and then washed twice with phosphate buffer at $\mathrm{pH}$ 7.2. The supernatant was discarded, and then $200 \mu \mathrm{L} 2.5 \%$ glutaraldehyde $(\mathrm{pH}=7.2)$ was added for sample fixation at room temperature for $2-3 \mathrm{~h}$. Subsequently, samples were re-washed twice as described above. Finally, samples were prepared by the FESEM or TEM (FEI Company, Quanta-200 and H-7650).

Assay of the $C$ and $D$ periods and $\mathbf{9 P C R}$ measurements. Measurement of the $\mathrm{D}$ period was based on measuring the ori/ter ratio by qPCR (Bio-Rad, Hercules, CA) as described in Liu et al. ${ }^{36}$ Two milliliter bacteria culture $\left(\mathrm{OD}_{600} \sim 0.4\right)$ was collected and immediately frozen in liquid nitrogen before sending to freezer for storage. After $24 \mathrm{~h}$, the bacteria genome was extracted using a bacteria total genome DNA extraction kit. The DNA concentration was quantified by measuring the absorbance at $260 \mathrm{~nm}$ UV light with the NanoDrop ND-1000 UV-Vis Spectrophotometer (Thermo Scientific). Primers were used for amplifying the DNA region proximal to the origin (oriC) and terminus (ter) ${ }^{57}$. The qPCR reactions were performed with a SuperReal Premix SYBR Green Plus kit according to its manual. For each PCR reaction, $20 \mu \mathrm{L}$ sample contained $10 \mathrm{ng}$ of DNA, $0.6 \mu \mathrm{M}$ of each primer and $10 \mu \mathrm{L}$ of $2 \times$ SYBR Green Supermix. The reaction process was carried out in an Opticon 2 Real-time PCR system (Bio-Rad, Hercules, CA, USA) according to the following protocol: $95^{\circ} \mathrm{C}$ for $3 \mathrm{~min}$, followed by 40 cycles of $95^{\circ} \mathrm{C}$ for $30 \mathrm{~s}, 60^{\circ} \mathrm{C}$ for $30 \mathrm{~s}$, and $72{ }^{\circ} \mathrm{C}$ for $30 \mathrm{~s}$. The qPCR product was checked in a $2 \%$ agarose gel to ensure the specificity of PCR amplification. The 16S rRNA was used as the reference gene to normalize the expression level. For each RNA preparation, at least three independent real-time PCR measurements were performed. RT-PCR primers were listed in Supplementary Table 2.

Calculation of the $\mathrm{C}$ period is based on Zhu et al. ${ }^{46}$ (Eqs. 3, 4). Briefly,

$$
\begin{gathered}
\text { ori } / \text { ter }=2^{(\mathrm{C} / \tau)} \\
\tau=\ln 2 / \mu,
\end{gathered}
$$

$\tau$ is the mass doubling time; $\mu$ is the specific growth rate.

The $\mathrm{C}$ period was measured by $\mathrm{qPCR}$, a DNA increment method was applied. Chloramphenicol was used to inhibit the initiation of new rounds of replication, cells were collected by filtration, and the DNA amount was measured by the diphenylamine colorimetric method. The $\mathrm{C}$ period was calculated by measuring DNA amount after inhibiting the replication initiation. After DNA initiation blockage corresponded to origins (Ori)/genome equivalents for the cell populations, the relative DNA amount was changed. Genome equivalents/cell was calculated using DNA/cell to divide the molecular mass of $E$. coli chromosome. $\mathrm{DNA} /$ cell was calculated by measuring total DNA/OD and cell count/OD ${ }^{46}$. Therefore, origins/cell was calculated by genome equivalents/cell times and the ori/ genome equivalents ratio. The D period was further derived based on Eq. 5 .

$$
\text { ori } / \text { cell }=2^{(\mathrm{C}+\mathrm{D}) / \tau} \text {, }
$$

Nile red staining. Cells ( $1 \mathrm{~mL}$ MR culture) were washed once with PBS, and then re-suspended in $1 \mathrm{~mL}$ PBS. Five microliter of Nile Red $\left(0.1 \mathrm{mg} \mathrm{mL}^{-1}\right.$ in acetone) was added to cell suspension, and then incubated at room temperature, after culturing $5 \mathrm{~min}$ with dark condition. Cells were washed twice by $100 \%$ ethanol and $75 \%$ ethyl alcohol, respectively. Cells were imaged with a Nikon eclipse $80 \mathrm{i}$ microscope (Nikon Corporation).

PI staining. The number of cells (about $10^{6}$ individual.mL $\mathrm{mL}^{-1}$ ) was collected for PI staining. Then, it were centrifuged at $500-1000 \mathrm{r} \cdot \mathrm{min}^{-1}$ for $5 \mathrm{~min}$ to discard culture medium. Next, cells were washed with $3 \mathrm{~mL}$ PBS twice, and centrifuged. After centrifugation, PBS was discarded. Cells were dyed by $1 \mathrm{~mL}$ PI dying at $4{ }^{\circ} \mathrm{C}$ for 5-30 min under the dark condition. Cells were imaged with a Nikon eclipse 80i microscope (Nikon Corporation). 
X-gal assay. The colorless compound X-gal (dissolved in $\mathrm{N}, \mathrm{N}$-dimethylformamide) could be converted into galactose by $\beta$-galactosidase, forming the blue substance 5-bromo-4-indigo. In this study, the engineered E. coli was transformed into the plates containing $40 \mu \mathrm{g} \mathrm{mL}-1 \mathrm{X}$-gal, and then cultured at $37^{\circ} \mathrm{C}$ for $32 \mathrm{~h}$ in the dark or irradiated with blue-light $\left(450 \mathrm{~nm}, 0.8 \mathrm{~W} / \mathrm{cm}^{2}\right)$. Based on this, the colony that produced $\beta$-galactosidase was turned into blue.

Creatine reaction assay. For creatine reaction assay, $10 \mathrm{~mL}$ reaction system included $10 \% \mathrm{NaOH}, 5 \%$ beta-naphthol (dissolves in n-propanol), $0.5 \%$ creatine, and deionized water. The proportion of the reaction assay was 1:1:1:7. Hundred microliter of fermentation broth was added into reaction system to start reaction in test tube. This reaction was lasted for $30 \mathrm{~min}$ at $30^{\circ} \mathrm{C}$. The red reaction liquid was positive with acetoin titer, and could be used as a qualitative detection method for instructing acetoin titer.

Flow cytometry assays. For flow cytometry analysis, E. coli cells were washed twice with PBS, and then resuspended to an $\mathrm{OD}_{600}$ of 0.2 . The assays were performed by a LSR Fortessa instrument (BD Biosciences) using DAPI (BFP) and PETxRed (mKate) channels. The voltage gains for each detector were set to DAPI, $407 \mathrm{~V}$ and PE-TxRed, $650 \mathrm{~V}$. Compensation was performed using cells that only expressed BFP or mKate. For each sample, at least 20,000 counts were recorded using a $0.5 \mathrm{~mL} \mathrm{~s}^{-1}$ flow rate. A gate was previously designed based on forward and side scatter ( $>99 \%$ cells were chosen for the analysis of fluorescence density percentage). All data were exported in FCS3 format and processed using FlowJo software (FlowJo-V10).

The bioimage of agarose plates. E. coli strains harboring BLAT, BLRT, NRAT, BANA, and BARNA systems were cultured overnight, respectively ${ }^{38}$. A photomask was placed on the bottom-side of the prepared agar plate and used aluminum oxide to avoid light illumination. Seed cultures were transferred to fresh medium for $\mathrm{OD}_{600}=0.8$, and then $400 \mu \mathrm{L}$ bacteria cultures was used to plate for bioimaging. The whole setup was kept inside the incubator at $37^{\circ} \mathrm{C}$. The LB plates were illuminated under $450 \mathrm{~nm}$ blue light or $650 \mathrm{~nm}$ NIR light or without illumination for $36 \mathrm{~h}$. Fluorescence images were collected by IBright FL1000 (Thermo Fisher) and ChemiScope 6000 (Shanghai Qinxiang Scientific Instrument co. LTD).

Cell viability assays. The viability of cells in $\mathrm{LB}$ plates was assessed by inoculating cells in fermentation medium. Cells were diluted to $\mathrm{OD}_{600}=0.5$ and $10 \mu \mathrm{L}$ of $10 \times$ serially diluted cell suspension was spread on each agar plate with different strains. Then, the LB plates were cultured with $37^{\circ} \mathrm{C}$ for $12 \mathrm{~h}$. Next, the numbers of living cell in different culture time and different strains were calculated.

Enzymatic assays. $\beta$-galactosidase ${ }^{39}$ gene was synthesized by GENEWIZ Biotechnology Co. LTD with codon optimization. ONPG (an analog of lactose) was used as substrates for assaying $\beta$-galactosidase activity. $\beta$-galactosidase could convert the colorless substrate oNPG into galactose and yellow-colored o-nitrophenol. o-Nitrophenol can be detected at $420 \mathrm{~nm}$ using a SpectraMax M3 plate reader. The diluted solution of $\beta$-galactosidase $(0.1 \mathrm{~mL})$ was added to $1.8 \mathrm{~mL}$ potassium phosphate buffer $(50 \mathrm{mM}, \mathrm{pH} 6.5)$ containing $20 \mathrm{mM}$ oNPG to start reaction. After incubation at $50{ }^{\circ} \mathrm{C}$ for $10 \mathrm{~min}$, this reaction was stopped by adding $1 \mathrm{~mL} 1 \mathrm{M} \mathrm{Na}_{2} \mathrm{CO}_{3}$. All the extracellular activity represented the extracellular activity per ml medium supernatant. The method of $\beta$-glucuronidase assay was similar to $\beta$-galactosidase. 4-Nitrophenyl- $\beta$-D-glucuronide was converted to $\mathrm{p}$ nitrophenol and $\beta$-gluconaldehyde glycoside by $\beta$-glucuronidase. For the enzymatic assay controlled by blue light or NIR light, culture temperature and rotation speed were set to $37^{\circ} \mathrm{C}$ and $200 \mathrm{rpm}$, respectively. Culture medium was refreshed every $12 \mathrm{~h}$ to clean the residual $\beta$-galactosidase or $\beta$-glucuronidase for next assays.

Assay of fluorescence intensity. The engineered E. coli strains used for assaying fluorescence intensity were plated on the LB plates for overnight at $37^{\circ} \mathrm{C}, 200 \mathrm{rpm}$. After that, it was inoculated into $50 \mathrm{~mL}$ fresh LB with $2 \%$ inoculum size (vol/vol), and then cultured at $37^{\circ} \mathrm{C}, 200 \mathrm{rpm}$. For assaying fluorescence intensity, the fluorescence of cell culture was detected by a SpectraMax M3 plate reader (Molecular Devices). The excitation and emission wavelengths of BFP were set at $402 \pm 10 \mathrm{~nm}$ and $457 \pm 10 \mathrm{~nm}$, respectively. The excitation and emission wavelengths of GFP were set at $480 \pm 10 \mathrm{~nm}$ and $515 \pm 10 \mathrm{~nm}$, respectively. The excitation and emission wavelengths of mKate were set at $588 \pm 10 \mathrm{~nm}$ and $645 \pm 10$ $\mathrm{nm}$, respectively. The excitation and emission wavelengths of DAPI were set at 358 $\pm 10 \mathrm{~nm}$ and $461 \pm 10 \mathrm{~nm}$, respectively.

Statistical and reproducibility. All data were expressed as mean \pm s.d. Differences between two groups were determined by two-tailed Student's $t$-test and paired sample analysis through SPSS statistics software (SPSS V13.0). We have repeated each experiment at least three times of biological independent experiments.

Reporting summary. Further information on research design is available in the Nature Research Reporting Summary linked to this article.

\section{Data availability}

Data supporting the findings of this work are available within the paper and its Supplementary Information files. A reporting summary for this Article is available as a Supplementary Information file. The datasets generated and analyzed during the current study are available from the corresponding author upon request. The source data underlying Figs. 1, 2, 3a, b, 4d-i, 5d-f, 6D-F, Tables 1, 2, as well as Supplementary Figures 1-12, 14, 15, 16b, c, 17, 18, 19B, 20-24, 26-31, 35-39 are provided in Source Data file. All SEM, TEM, fluorescence, bio-imaging pictures, and enzyme reaction of micrographs are also available at figshare (https://figshare.com/search?q=10.6084\% 2Fm9.figshare.9122534\&searchMode=1).

Received: 14 September 2019; Accepted: 19 April 2020; Published online: 08 May 2020

\section{References}

1. Nielsen, J. \& Keasling, J. D. Engineering cellular metabolism. Cell 164, 1185-1197 (2016)

2. Skjoedt, M. L. et al. Engineering prokaryotic transcriptional activators as metabolite biosensors in yeast. Nat. Chem. Biol. 12, 951-961 (2016).

3. Lee, S. Y. \& Hyun, Uk,K. Systems strategies for developing industrial microbial strains. Nat. Biotechnol. 33, 1061-1072 (2015).

4. Yu, T. et al. Reprogramming yeast metabolism from alcoholic fermentation to lipogenesis. Cell 174, 1549-1558 (2018).

5. Luo, X. Z. et al. Complete biosynthesis of cannabinoids and their unnatural analogues in yeast. Nature 567, 123-135 (2019).

6. Huang, M. T., Bao, J., Hallstrom, B. M., Petranovic, D. \& Nielsen, J. Efficient protein production by yeast requires global tuning of metabolism. Nat. Commun. 8, 1131-1143 (2017).

7. Lee, S. Y. et al. A comprehensive metabolic map for production of bio-based chemicals. Nat. Catal. 2, 18-33 (2019).

8. Zhou, Y. J. Expanding the terpenoid kingdom. Nat. Chem. Biol. 14, 1069-1070 (2018).

9. Zhou, Y. J., Kerkhoven, E. J. \& Nielsen, J. Barriers and opportunities in biobased production of hydrocarbons. Nat. Energy 3, 925-935 (2018).

10. Chen, X. L. et al. DCEO biotechnology: tools to design, construct, evaluate, and optimize the metabolic pathway for biosynthesis of chemicals. Chem. Rev. 118, 4-72 (2018).

11. Sun, X. X. et al. Synthesis of chemicals by metabolic engineering of microbes. Chem. Soc. Rev. 44, 3760-3785 (2015).

12. Delebecque, C. J., Lindner, A. B., Silver, P. A. \& Aldaye, F. A. Organization of intracellular reactions with rationally designed RNA assemblies. Science 333 470-474 (2011)

13. Jiang, X. R. \& Chen., G. Q. Morphology engineering of bacteria for bioproduction. Biotechnol. Adv. 34, 435-440 (2016).

14. Song, H., Ding, M. Z., Jia, X. Q., Ma, Q. \& Yuan, Y. J. Synthetic microbial consortia: from systematic analysis to construction and applications. Chem. Soc. Rev. 43, 6954-6981 (2014).

15. Timoumi, A., Guillouet, S. E., Molina-Jouve, C., Fillaudeau, L. \& Gorret, N. Impacts of environmental conditions on product formation and morphology of Yarrowia lipolytica. Appl. Microbiol. Biotechnol. 102, 3831-3848 (2018).

16. Kusumawardhani, H., Hosseini, R. \& de Winde, J. H. Solvent tolerance in bacteria: fulfilling the promise of the biotech era? Trends Biotechnol. 36, 1025-1039 (2018).

17. Spencer, R. S. et al. A stabilized microbial ecosystem of self-limiting bacteria using synthetic quorum-regulated lysis. Nat. Microbiol. 2, 1-9 (2017).

18. Din, M. O. et al. Synchronized cycles of bacterial lysis for in vivo delivery. Nature 536, 81-85 (2016).

19. Basan, M. et al. Inflating bacterial cells by increased protein synthesis. Mol. Syst. Biol. 11, 223-229 (2015).

20. Driouch, H., Hansch, R., Wucherpfennig, T., Krull, R. \& Wittmann, C. Improved enzyme production by bio-pellets of Aspergillus niger: targeted morphology engineering using titanate microparticles. Biotechnol. Bioeng. 109, 462-471 (2012).

21. Du, S. \& Lutkenhaus, J. Assembly and activation of the Escherichia coli divisome. Mol. Microbiol. 105, 177-187 (2017).

22. Budin, I. et al. Viscous control of cellular respiration by membrane lipid composition. Science 362, 1186-1189 (2018).

23. Botero, S., Chiaroni-Clarke, R. \& Simon, S. M. Escherichia coli as a platform for the study of phosphoinositide biology. Sci. Adv. 5, 4872-4888 (2019).

24. Zhang, X. C. et al. Engineering cell wall synthesis mechanism for enhanced PHB accumulation in E. coli. Metab. Eng. 45, 32-46 (2017).

25. Shi, H. et al. Deep phenotypic mapping of bacterial cytoskeletal mutants reveals physiological robustness to cell size. Curr. Biol. 27, 3419-3429 (2017).

26. Dewachter, L., Verstraeten, N., Fauvart, M. \& Michiels, J. An integrative view of cell cycle control in Escherichia coli. FEMS Microbiol. Rev. 42, 116-136 (2018). 
27. Willis, L. \& Huang, K. C. Sizing up the bacterial cell cycle. Nat. Rev. Microbiol. 15, 606-620 (2017).

28. Kureisaite-Ciziene, D. et al. Structural analysis of the interaction between the bacterial cell division proteins fts $Q$ and ftsB. MBio 9, e01346-01318 (2018).

29. Ward, J. E. \& Lutken, J. Overproduction of FtsZ induces minicell formation in E. coli. Cell 42, 941-949 (1985).

30. Jeong, K. J. \& Lee, S. Y. Enhanced production of recombinant proteins in Escherichia coli by filamentation suppression. Appl. Environ. Microbiol. 69, 1295-1298 (2003).

31. Bisicchia, P., Arumugam, S., Schwille, P. \& Sherratt, D. MinC, MinD, and MinE drive counter-oscillation of early-cell-division proteins prior to Escherichia coli septum formation. MBio 4, e00856-00813 (2013).

32. Auer, G. K. et al. Bacterial swarming reduces proteus mirabilis and Vibrio parahaemolyticus cell stiffness and increases beta-Lactam susceptibility. Mbio 10, e00210-e00219 (2019).

33. Zhao, E. M. et al. Optogenetic regulation of engineered cellular metabolism for microbial chemical production. Nature 555, 683-687 (2018).

34. Shao, J. W. et al. Synthetic far-red light-mediated CRISPR-dCas9 device for inducing functional neuronal differentiation. Proc. Natl Acad. Sci. USA 115, E6722-E6730 (2018)

35. Zhao, E. M. et al. Light-based control of metabolic flux through assembly of synthetic organelles. Nat. Chem. Biol. 15, 589-597 (2019).

36. Zheng, H. et al. Interrogating the Escherichia coli cell cycle by cell dimension perturbations. Proc. Natl Acad. Sci. USA 113, 15000-15005 (2016).

37. Strahl, H., Burmann, F. \& Hamoen, L. W. The actin homologue MreB organizes the bacterial cell membrane. Nat. Commun. 5, 25-36 (2014).

38. Jayaraman, P. et al. Blue light-mediated transcriptional activation and repression of gene expression in bacteria. Nucleic Acids Res. 44, 6994-7005 (2016).

39. Ryu, M. H. \& Gomelsky, M. Near-infrared light responsive synthetic c-diGMP module for optogenetic applications. ACS Synth. Biol. 3, 802-810 (2014).

40. Guo, L. et al. Enhancement of malate production through engineering of the periplasmic rTCA pathway in Escherichia coli. Biotechnol. Bioeng. 115, 1571-1580 (2018).

41. Mao, Y. F. et al. Systematic metabolic engineering of Corynebacterium glutamicum for the industrial-level production of optically pure D-acetoin. Green. Chem. 19, 5691-5702 (2017).

42. Battesti, A., Majdalani, N. \& Gottesman, S. The rpoS-mediated general stress response in Escherichia coli. Annu. Rev. Microbiol. 65, 189-213 (2011).

43. Choi, S. Y. et al. One-step fermentative production of poly(lactate-coglycolate) from carbohydrates in Escherichia coli. Nat. Biotechnol. 34, 435-441 (2016).

44. Huang, Y., Xia, A., Yang, G. \& Jin, F. Bioprinting living biofilms through optogenetic manipulation. ACS Synth. Biol. 7, 1195-1200 (2018).

45. Lee, S. Y., Lee, K. M. \& Chan, H. N. Comparison of recombinant Escherichia coli strains for synthesis and morphological changes. Biotechnol. Bioeng. 44, 1337-1347 (1994).

46. Zhu, M. L. et al. Manipulating the bacterial cell cycle and cell size by titrating the expression of ribonucleotide reductase. Mbio 16, 38-51 (2017).

47. Chen, X. L., Zhou, J., Ding, Q., Luo, Q. L. \& Liu, L. M. Morphology engineering of Aspergillus oryzae for L-malate production. Biotechnol. Bioeng. 116, 2662-2673 (2019).

48. Liao, W., Liu, Y. \& Chen, S. L. Studying pellet formation of a filamentous fungus Rhizopus oryzae to enhance organic acid production. Appl. Biochem. Biotechnol. 137, 689-701 (2007).

49. Choe, D. et al. Adaptive laboratory evolution of a genome-reduced Escherichia coli. Nat. Commun. 10, 1-14 (2019).

50. Zhang, L. J. et al. Biotechnological production of acetoin, a bio-based platform chemical, from a lignocellulosic resource by metabolically engineered Enterobacter cloacae. Green. Chem. 18, 1560-1570 (2016).

51. Wang, Y., Ling, C., Chen, Y., Jiang, X. \& Chen, G. Q. Microbial engineering for easy downstream processing. Biotechnol. Adv. 15, 15-24 (2019).

52. Jung, Y. K., Kim, T. Y., Park, S. J. \& Lee, S. Y. Metabolic engineering of Escherichia coli for the production of polylactic acid and its copolymers. Biotechnol. Bioeng. 105, 161-171 (2010).

53. Durante-Rodriguez, G., de Lorenzo, V. \& Nikel, P. I. A post-translational metabolic switch enables complete decoupling of bacterial growth from biopolymer production in engineered Escherichia coli. ACS Synth. Biol. 7, 2686-2697 (2018).

54. Ling, C. et al. Engineering $\mathrm{NADH} / \mathrm{NAD}^{+}$ratio in Halomonas bluephagenesis for enhanced production of polyhydroxyalkanoates (PHA). Metab. Eng. 49, 275-286 (2018).

55. Wang, S. H., Hou, Y. R., Chen, X. L. \& Liu, L. M. Kick-starting evolution efficiency with an autonomous evolution mutation system. Metab. Eng. 54, 127-136 (2019).

56. $\mathrm{Hu}$, G. P. et al. Engineering synergetic $\mathrm{CO}_{2}$-fixing pathways for malate production. Metab. Eng. 47, 496-504 (2018).

57. Waldminghaus, T., Weigel, C. \& Skarstad, K. Replication fork movement and methylation govern SeqA binding to the Escherichia coli chromosome. Nucleic Acids Res. 40, 5465-5476 (2012).

\section{Acknowledgements}

This work was supported by the National Key R\&D Program of China (2019YFA0904900), the National Natural Science Foundation of China (21978113), the Key Technologies R\&D Program of Jiangsu Province (BE2017622), the Fundamental Research Funds for the Central Universities (JUSRP22031), and the National First-Class Discipline Program of Light Industry Technology and Engineering (LITE2018-08).

\section{Author contributions}

Q.D., X.L.C., and L.M.L. conceived this project and designed the experiments. Q.D. and Y.L. constructed the strains and plasmids. Q.D. and D.L.M. performed the experiments that are shown in Figs. 1, 2, 3 and Supplementary Figs. 1-20. Q.D. and Y.L. performed the experiments that are shown in Figs. 4-6 and Supplementary Figs. 21-39. J.L. Q.D. and Y.L. conducted and interpreted all fermentation experiments. L.G., C.G., C.Y., J.L. and G.P.H. provided technical assistance. X.L.C., L.M.L., and G.Q.L. provided overall project supervision. Q.D. analyzed the data and wrote the manuscript. All authors reviewed and approved the manuscript.

\section{Competing interests}

The authors declare no competing interests.

\section{Additional information}

Supplementary information is available for this paper at https://doi.org/10.1038/s41467020-16154-3.

Correspondence and requests for materials should be addressed to X.C.

Peer review information Nature Communications thanks Guo-Qiang Chen, Shang-Tian Yang and the other, anonymous, reviewer(s) for their contribution to the peer review of this work.

Reprints and permission information is available at http://www.nature.com/reprints

Publisher's note Springer Nature remains neutral with regard to jurisdictional claims in published maps and institutional affiliations.

Open Access This article is licensed under a Creative Commons Attribution 4.0 International License, which permits use, sharing, adaptation, distribution and reproduction in any medium or format, as long as you give appropriate credit to the original author(s) and the source, provide a link to the Creative Commons license, and indicate if changes were made. The images or other third party material in this article are included in the article's Creative Commons license, unless indicated otherwise in a credit line to the material. If material is not included in the article's Creative Commons license and your intended use is not permitted by statutory regulation or exceeds the permitted use, you will need to obtain permission directly from the copyright holder. To view a copy of this license, visit http://creativecommons.org/ licenses/by/4.0/.

(C) The Author(s) 2020, corrected publication 2020 